\title{
Iterative Learning Control of a Fully Flexible Valve Actuation System for Non-throttled Engine Load Control
}

\author{
A THESIS \\ SUBMITTED TO THE FACULTY OF THE GRADUATE SCHOOL \\ OF THE UNIVERSITY OF MINNESOTA \\ BY
}

Adam James Heinzen

IN PARTIAL FULFILLMENT OF THE REQUIREMENTS

FOR THE DEGREE OF

MASTER OF SCIENCE

Professor Zongxuan Sun

May, 2011 
(c) Adam James Heinzen 2011

ALL RIGHTS RESERVED 


\section{Acknowledgements}

To all those who helped me on my journey through graduate school, especially:

Pradeep Kumar Reddy Gillella, for his invaluable assistance throughout my graduate career,

Professor Zongxuan Sun, for his guidance, advice, teaching, and assistance,

Professors Rajesh Rajamani and Yiyuan Zhao, for teaching me control theory and for serving on my defense committee,

The faculty of the Mechanical Engineering department, especially Professors Thomas Chase, Frank Kelso, David Kittelson, and Susan Mantell, for being teachers and friends,

Fellow graduate students Matt McCuen, Xingyong Song, and Yu Wang, for their assitance and inspiration

The staff of the Mechanical Engineering department, especially John Gardner and Holly Edgett, for their help navigating the troubled waters of paperwork and copy machines,

Mechanical Engineering subject librarian Jon Jeffryes, for his invaluable assistance in my literature search,

And my family, for their support. 


\section{Dedication}

To all my friends, especially

AB BD ST AV 


\begin{abstract}
This thesis presents the iterative learning control of a fully flexible valve actuation system for non-throttled load control of an internal combustion engine. First, a description is given of a novel camless valve actuation system with a unique hydro-mechanical internal feedback mechanism which simplifies the external control design. All the critical parameters describing the engine valve event, i.e. lift, timing, duration and seating velocity can be continuously varied by controlling the triggering timings of three two-state valves. Initial testing of a prototype experimental setup reveals that the performance of the system (transient tracking and steady-state variability) is influenced purely by the state of the system when the internal feedback mechanism is activated. This feature motivates the development of a cycle-to-cycle learning-based external control for activating the internal feedback mechanism based on the desired valve profile characteristics and the system state. To verify the proposed control methodology, it is implemented on the experimental system to track reference trajectories for the various valve event parameters corresponding to the non-throttled load control of an engine during the U.S. Federal Test Procedure (FTP) urban driving cycle. Vehicle load demand analysis is used to compute the desired engine speed and torque requirements. Detailed dynamic valve flow simulations assuming full flexibility of the engine valve event parameters are used to calculate the required trajectory of all these parameters to satisfy the speed and torque requirements without the use of a throttle. The experimental results show that the proposed framework, i.e., the valve actuation system and the external control methodology, is able to provide excellent performance even during aggressive transient operation. Over the 19145 valve events of the FTP cycle, 99\% of cycles had lift errors of $0.203 \mathrm{~mm}$ or less, and $99 \%$ of cycles had duration errors of 4.87 crank-angle degrees or less. Furthermore, only $11.99 \%$ of cycles had seating velocities higher than the desired bound; $99 \%$ of cycles had seating velocities $0.0429 \mathrm{~m} / \mathrm{s}$ or less over the desired bound.
\end{abstract}




\section{Contents}

Acknowledgements i

Dedication ii

Abstract iii

List of Tables vi vi v v v v

List of Figures vii

1 Introduction 1

2 Electro-hydraulic Fully-Flexible Valve Actuation System with Internal Feedback 6

2.1 System Design and Operation . . . . . . . . . . . . . . . 6

2.2 System Characteristics and Challenges . . . . . . . . . . . . . . . 9

3 Design of Iterative Learning Controllen 11

3.1 Review of Iterative Learning Control . . . . . . . . . . . . . . . . . . . . . . 11

3.2 Control Overview . . . . . . . . . . . . . . . . . 15

3.3 Lift controller . . . . . . . . . . . . . . . . . . . . . 17

3.4 Seating controllen . . . . . . . . . . . . . . . . . . . . . 19

4 Review of Non-throttled Engine Load Control 25

4.1 NTELC via Lean-Burn Capability . . . . . . . . . . . . . . . . . 26

4.2 NTELC via Intake Regulation . . . . . . . . . . . . . . . . 28 
5 Vehicle Load Demand Analvsis and Non-throttled Engine Load Control 31

5.1 Vehicle Load Demand Analysis . . . . . . . . . . . . . . . . . . . 32

5.2 Engine Speed and Load Calculation . . . . . . . . . . . . . . . . 34

5.3 Required Air Mass Calculation . . . . . . . . . . . . . . . . . . 36

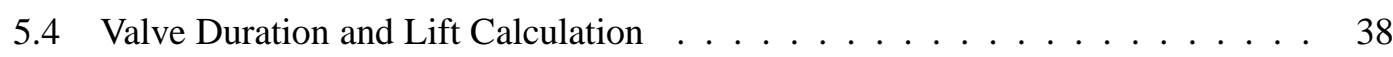

6 Simulation and Experimental Results

$6.1 \quad$ FTP Cycle Results . . . . . . . . . . . . . . . . . . . . . 44

6.2 Valve Tracking Results $\ldots \ldots \ldots \ldots \ldots \ldots$. . . . . . . . . . . 48

7 Discussion and Conclusion $\quad 53$

References

$\begin{array}{ll}\text { Appendix A. Acronyms } & 60\end{array}$ 


\section{List of Tables}

5.1 Vehicle parameter values used in load demand analysis $\ldots . . \ldots 33$

6.1 Kev statistics from tracking of FTP cycle data $\ldots \ldots \ldots$. . . . . . . 50

A.1 Acronyms ............................ 60 


\section{List of Figures}

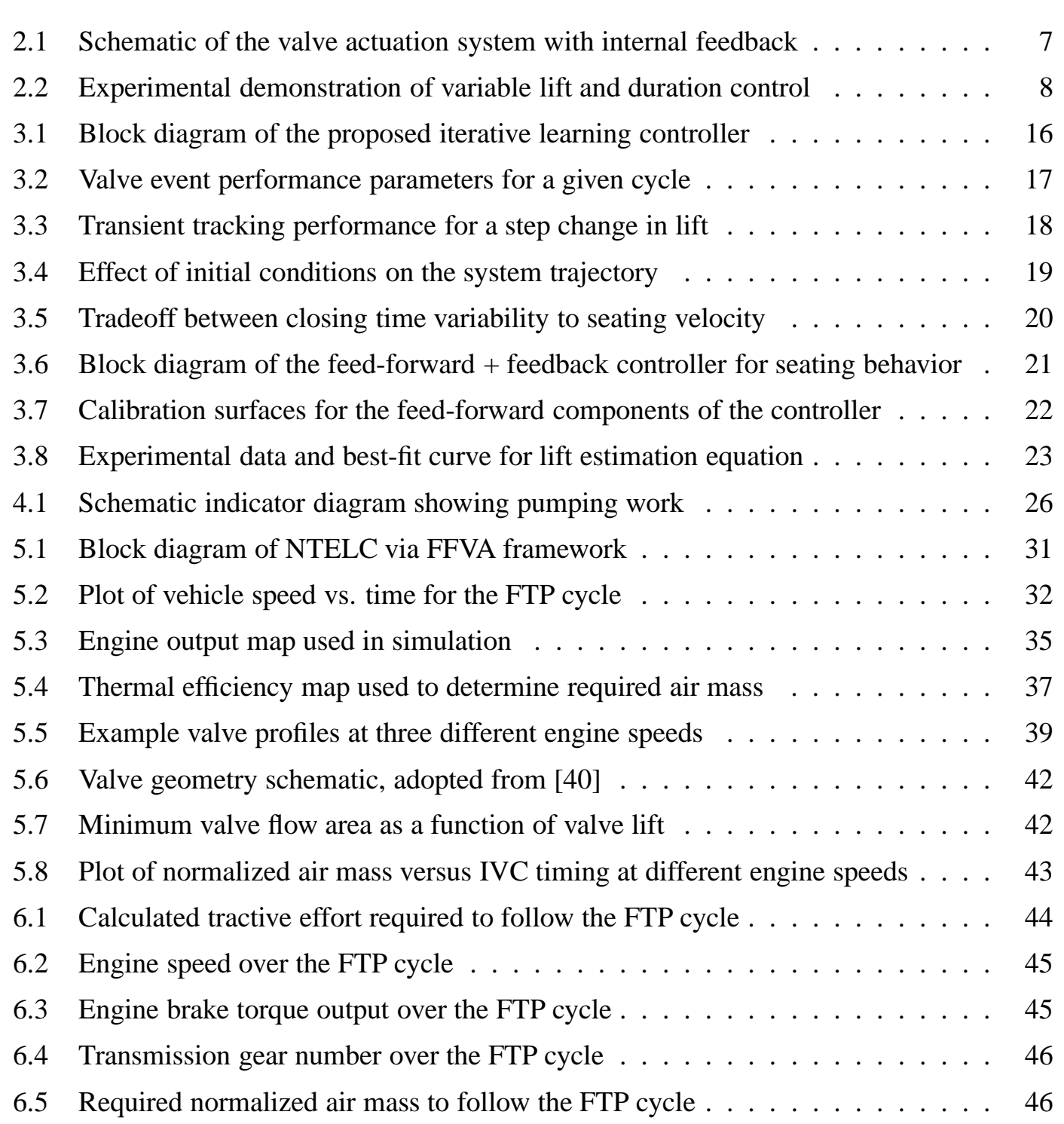


6.6 Maximum valve lift trace over the FTP cycle. . . . . . . . . . . . . . . . . . 47

6.7 Intake valve closing time traces over the FTP cycle $\ldots \ldots$. . . . . . . . 47

6.8 Prototype experimental setup . . . . . . . . . . . . . . . . . 48

6.9 Lift tracking error for controller over FTP cvcle . . . . . . . . . . . . . . . 49

6.10 IVC tracking error for controller over FTP cvcle . . . . . . . . . . . . . 50

6.11 Seating velocity and desired seating velocity bound over FTP cycle . . . . . . . 51

6.12 Lift tracking statistics over FTP cycle . . . . . . . . . . . . . 51

6.13 Duration tracking statistics over FTP cycle . . . . . . . . . . . . . 52

6.14 Seating velocity violation tracking statistics over FTP cycle . . . . . . . . . 52 


\section{Chapter 1}

\section{Introduction}

Internal combustion engines (ICEs) are widely used as the power source for many applications, including automobiles, locomotives, ships, electric generators, etc. Problems associated with ICEs include greenhouse gas emissions, chemical and particulate pollutant emissions, and the dwindling supply of fossil fuels. Despite being over 100 years old, the ICE is still preferred due to the high energy density of hydrocarbon fuels and the power density of the ICE. Thus, there is a strong motivation to increase the efficiency of the ICE.

One particular point regarding ICEs relates to the fact that their high power density and the high energy density of their fuels make them ideal for mobile applications. However, the variation in operating conditions inherent to these mobile applications, coupled with the variation in the efficiency of ICEs with operating condition, means that these engines are often forced to operate in relatively low-efficiency regions. More flexibility in available controls will allow the engine to operate near its peak efficiency more of the time.

Variable valve actuation is one such flexibility that can provide many advantages in efficiency and emissions. The majority of reciprocating ICEs use one or more camshafts with eccentric lobes to actuate the intake and exhaust valves that control the flow of air, fuel, and combustion products in and out of the cylinders. However, the fixed geometry of these cams means that the valve lift profiles for the engine are fixed, irrespective of load, engine speed, or any other potentially relevant variables. Variable valve actuation schemes utilizing cams have been implemented allowing two discrete camshaft profiles [1], two discrete lifts with variable phasing [2], and variable phasing and lift [3], to list three examples. However, the use of the camshaft imposes limits on the range of variability of lift and phasing, and makes duration 
adjustment difficult.

Fully-flexible valve actuation (FFVA) or "camless" systems allow infinite variation of lift, timing, and duration over a wide range. This flexibility has distinct advantages in efficiency and emissions. It facilitates the following alternate strategies:

- throttle-less operation [3, 4, 5, 6] (discussed in much more detail in Chapter 4),

- cylinder deactivation [6], 7],

- valve deactivation and using unequal valve lifts in multi-valve cylinder heads to manage in-cylinder airflow [6],

- changing the engine's effective compression ratio via early and late intake-valve closing (IVC) strategies [4, 6, 8],

- pneumatic hybridization during engine braking [6], and

- the control of homogeneous-charge compression ignition (HCCI) [8].

A more rigorous discussion on the benefits of flexibility in valve actuation can be found in [3, 4, 5, 6, 7, 8, 9].

However, the removal of the mechanical linkage between the valves and the crankshaft demands reliable, real-time control of the valve profile by the engine computer to ensure proper operation. Most previous FFVA implementations, for example [10 11], are based on the use of complex feedback controllers to monitor the valve's position and calculate the appropriate control action for the actuator in real time. This approach demands accurate, low-noise position sensors and powerful microprocessors to enable low-latency, real-time calculation of the control effort. In addition, accurate and high-bandwidth actuators are needed to control the valve to the desired position, even at high engine speeds. As such, this strategy may be expensive and difficult to implement on a production engine.

A production-oriented camless system is required to operate with the same level of accuracy and repeatability as existing cam-based systems to ensure proper engine operation and to avoid valve-piston interference [4] 12]. Such a system is also required to be relatively inexpensive to manufacture while having sufficient bandwidth to allow high-speed engine operation. To ensure accurate valve positioning, repeatability, and robustness to disturbances, the control system must be suited for mass production; i.e., it should use low-cost sensors, control algorithms 
capable of operating on the engine's control unit with a relatively low computational burden, and should require minimum calibration. Finally, to satisfy noise and wear constraints, the system must be capable of sufficiently low valve seating velocities.

This thesis presents the control design for a production-oriented FFVA system based on a hydro-mechanical internal feedback system [12] 13, 14]. It was observed that, for a given physical design of this system, its trajectory (and consequently the performance parameters corresponding to the engine valve event) is dependent only on the initial state of the hydromechanical internal feedback system. The initial conditions can be modified in real time by adjusting the triggering timings of simple two-state valves. However, the triggering timings of these two-state valves corresponding to optimal performance vary with system operating conditions, thus making the use of calibration-based open-loop controllers intractable. An iterativelearning-based controller capable of modifying the initial conditions by adjusting the timing of the activation/deactivation of the hydro-mechanical feedback loop to achieve the required performance objectives is thus proposed.

The system performance parameters (lift, duration, and seating velocity) are all scalars, which need to be evaluated only once at the end of each cycle. This relaxes the demand for noise-free position sensors and also decreases the computational burden. The control inputs (time at which the internal feedback system is engaged) need to be computed only once for each engine cycle (at the start of the cycle). The engine valves will be open for about one-fourth to one-third of the engine's 720-crank-angle-degree (CAD) cycle. This eases the real-time processing constraint, as the actions for the next valve event can be calculated after the current event during the remaining time (approximately $480 \mathrm{CAD}$ ).

The proposed iterative learning controller utilizes the errors in lift, duration, and seating velocity from each cycle to appropriately modify the triggering timings of the two-state valves for the next cycle to ensure convergence to the desired values of the performance parameters. This cycle-to-cycle feedback is combined with a calibrated feedforward component to ensure rapid transient response and to compensate for the interaction between seating velocity and engine valve closing time. The seating velocity controller is structured to obey a desired seating velocity bound, while dynamically tuning itself to minimize closing time variability. This finds the ideal operating point balancing the present FFVA system's inherent trade-off between low closing time variability and low seating velocity. 
It should be noted that the additional flexibility given by the FFVA system means that desired values for valve lift, duration, timing, and seating velocity must be calculated and provided to the lower-level controller discussed above. These values must be selected to ensure proper engine operation, given the requirements of the application; for example, if the engine in question is installed in an automobile, the driver's input and the vehicle operating conditions require a certain engine speed and load trajectory that the FFVA system must help accomplish.

To that end, a systematic method of calculating these desired performance parameter values is developed for the non-throttled engine load control of a spark-ignition engine. This method is generalized; that is, it is applicable to a wide range of vehicles and engines, given the proper parameter values, engine and transmission characteristics, etc. It begins by using a desired vehicle speed and acceleration to perform a vehicle load analysis, moves on to a calculation of required engine speed and load, finds the required mass of air to be introduced to each cylinder, and uses a detailed valve flow simulation to calculate the desired engine valve duration. To simplify the dimensionality of the problem, valve event timing is fixed, and desired lift and maximum seating velocity bound are fixed as a function of engine speed.

The Federal Test Procedure, an urban driving cycle lasting more than 30 minutes, is used as a demonstration of this systematic method. Beginning with a prescribed vehicle speed, desired engine valve performance parameter trajectories are calculated. These trajectories are then used as realistic examples of real-world driving conditions to demonstrate the effectiveness of the lower-level iterative learning controller in tracking any arbitrary desired performance parameter trajectory.

The rest of this thesis is organized as follows:

- Chapter 2 presents an overview of the design of the present electro-hydraulic camless system and its internal feedback system.

- In Chapter 3, a review of iterative learning control is presented, followed by the development of a suitable iterative learning controller for this system.

- Chapter 4 contains a review of non-throttled engine load control.

- Chapter 5 details vehicle load analysis and the calculations of desired valve parameters for non-throttled engine load control.

- Chapter 6 presents the results of this non-throttled engine load control process, along 
with experimental results showing a hardware system and the controller developed in Chapter 3 tracking the traces calculated in Chapter [5, using the Federal Test Procedure (FTP) cycle as an example.

- Chapter 7 presents final discussion, analysis, and conclusions of the work developed in this thesis. 


\section{Chapter 2}

\section{Electro-hydraulic Fully-Flexible Valve Actuation System with Internal Feedback}

The concept of a new production-oriented FFVA system based on an internal feedback mechanism was first presented in [13]. [12] addressed some of the design and sizing considerations for the system and also demonstrated the effectiveness of the concept using a prototype experimental setup. [14] presented a mathematical model for the system, which was verified experimentally and used for the design of a critical subsystem to improve the performance and robustness of the system.

\subsection{System Design and Operation}

Fig. 2.1 shows a schematic of a valve actuator with the internal feedback system. The highpressure rail and the low-pressure reservoir are common to all actuators. Components $\{1\}$ through $\{5\}$ together constitute the actuator for one engine valve. Component $\{3\}$ is a twoposition, three-way solenoid valve, which connects the entire system to the high-pressure rail or to the reservoir. Component $\{4\}$ is the spring-returned hydraulic actuator, which is in contact with the engine valve's stem. Component $\{5\}$ is a spool valve, which controls the fluid flow to and from the main actuator chamber (a). It is designed such that the flow rate is maximum when 


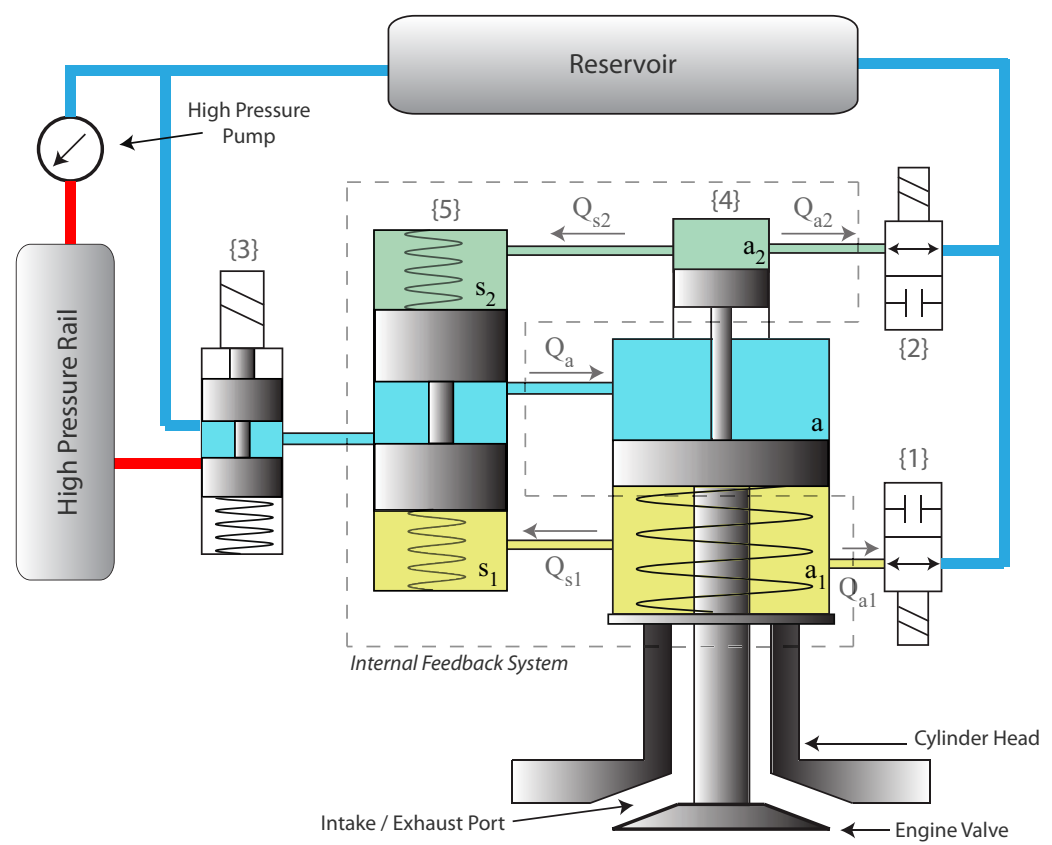

Figure 2.1: Schematic of the valve actuation system with internal feedback

the spool is at the center position and decreases as the spool is deflected in either direction. The position of the spool is dependent on the pressure of the fluid in the $\left(\mathrm{s}_{1}\right)$ and $\left(\mathrm{s}_{2}\right)$ fluid chambers, which are in turn dependent on the pressure in the $\left(a_{1}\right)$ and $\left(a_{2}\right)$ fluid chambers of the actuator. Components $\{1\}$ and $\{2\}$ are two-way, on-off valves that allow or block fluid flow between the actuator's bottom $\left(\mathrm{a}_{1}\right)$ and top $\left(\mathrm{a}_{2}\right)$ fluid chambers, respectively, and the reservoir.

When all the valves $\{1\},\{2\}$ and $\{3\}$ are in the de-energized state, the actuator's main chamber (a) is connected to the reservoir and the spring force keeps the engine valve in the closed position. Chambers $\left(\mathrm{s}_{1}\right),\left(\mathrm{s}_{2}\right),\left(\mathrm{a}_{1}\right)$ and $\left(\mathrm{a}_{2}\right)$ are all connected to the reservoir. This enables the springs to hold the spool $\{5\}$ in the middle position, which allows maximum flow to and from the actuator.

To open the engine valve, the three-way solenoid valve $\{3\}$ is energized to connect the actuator's main fluid chamber to the high-pressure rail which opens the engine valve. To control the lift of the engine valve, on-off valve $\{1\}$ is closed at a predetermined timing during the actuator's opening stroke. This blocks the flow from $\left(\mathrm{a}_{1}\right)$ to the low-pressure reservoir and 
diverts it to $\left(\mathrm{s}_{1}\right)$ of the spool valve, which pushes the spool upwards and hence reduces the flow to the actuator. The decrease in flow gradually decelerates the actuator until it comes to rest at a position corresponding to the fully deflected position of the spool. Fig. 2.2 a) presents experimental data in which different valve lifts were obtained by varying the relative triggering time of the on-off valve $\{1\}$ with respect to the three-way valve's triggering timing, which occurs at $t=0$ seconds in both Fig. 2.2 (a) and (b).

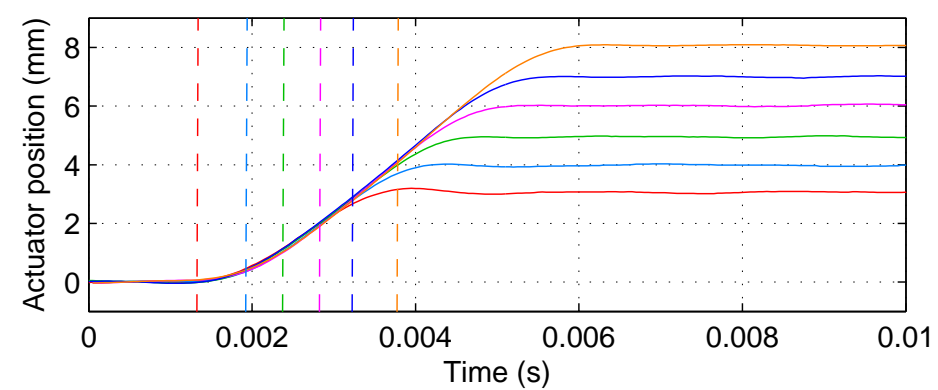

(a)

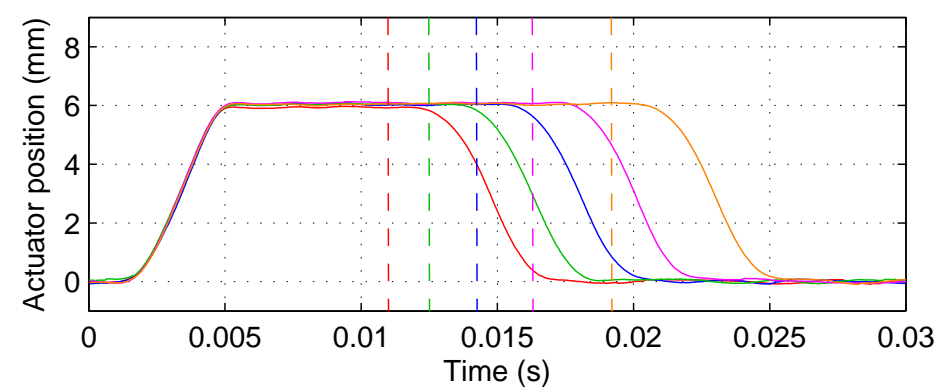

(b)

Figure 2.2: Experimental demonstration of the variable lift and duration control capability of the new valve actuation system

To close the engine valve, the three-way valve $\{3\}$ and the on-off valve $\{1\}$ are both deenergized. The spool in $\{5\}$ returns to the center position and thus connects the actuator's main chamber to the low-pressure reservoir which causes the engine valve to close due to the force of the return spring. During the engine valve's upward motion, the fluid from $\left(\mathrm{a}_{2}\right)$ is pushed into the low-pressure reservoir. As the valve approaches the closed position, the on-off valve $\{2\}$ is energized. This diverts the fluid from $\left(\mathrm{a}_{2}\right)$ to $\left(\mathrm{s}_{2}\right)$. The spool is deflected downwards and hence restricts the flow out of the actuator's main chamber, which in turn decelerates the actuator. 
By varying the triggering timing of the three-way valve $\{3\}$ and on-off valve $\{2\}$, the engine valve's closing timing and its seating velocity can both be controlled precisely. Fig. 2.2 b) shows five different valve profiles together with the corresponding three-way valve off timings to demonstrate the ability to control the engine valve's closing timing (duration). The seating velocity behavior is demonstrated Chapter 3 . Note that it is straightforward to alter the timing of the valve event simply by adjusting when the three-way valve $\{3\}$ is energized.

\subsection{System Characteristics and Challenges}

From the design and operation of the system, it becomes clear that the choice of triggering timing for the three-way and the on-off valves determines all the valve event characteristics (timing, lift, duration, and seating velocity) for a given cycle. This greatly simplifies the control of the system. When compared to other actuation systems [10, 11] that rely on traditional realtime sample-to-sample feedback control, this architecture requires only that the values for the control inputs (triggering timings) be computed for each cycle.

The on-off valves $\{1\}$ and $\{2\}\left(u_{1}, u_{2}\right)$ can be triggered either at a predetermined time (CAD) or at a predetermined engine valve displacement to achieve the required performance. Both of these implementations have their own advantages and disadvantages. Triggering based on displacement is inherently robust and requires little calibration, as the engine valve displacement after an on-off valve is triggered is fixed depending on the ratios of piston areas $s_{1} / a_{1}$ and $\mathrm{s}_{2} / \mathrm{a}_{2}$ (see Fig. 2.1). This approach also has the advantage of being insensitive to engine speed. However, it requires real-time monitoring of the engine valve's position. This renders filtering the displacement sensor's output unattractive due to the effect of filter delay, which thus requires the use of a higher-cost, lower-noise displacement sensor to ensure accurate triggering. For a fixed triggering position, closing time and seating velocity will vary based on the lift from which the valve is returning (due to variation in velocity at the instant when the on-off valve is triggered) as demonstrated in Fig. 3.4 in Chapter 3 .

Triggering based on timing (CAD) allows filtering of displacement data (needed only for performance parameter calculations, which can be performed just before the start of the next cycle). This allows the use of lower-cost displacement sensors and an encoder to measure the crankshaft orientation. However, the triggering timings in CAD will vary with supply pressure, engine speed, and valve lift. A calibration-based open-loop control of the timing for all possible 
engine valve events and operating conditions would be extremely tedious, if not intractable.

For both schemes, some uncertainty will be present due to the switching times of the onoff valves and hydraulic delays in the IFS circuits. A cycle-to-cycle learning control scheme would be able to find and adjust the timing or displacement at which the control valves are triggered based on the required performance and the operating point of the system. This would allow the system to adapt to changes in engine operating conditions, which are likely to change slowly when compared to the length of the engine cycle. In addition, it would help alleviate the calibration requirements of a pure open-loop controller, making this type of control attractive for production-oriented implementation.

By the nature of the system, the three-way valve triggering $\left(u_{3}\right)$ must be implemented in the time (or CAD) domain. The controller presented here is designed to utilize either CAD-based triggering or position-based triggering for $u_{1}$ and $u_{2}$. Experimental results will be presented for a controller that utilizes CAD-based triggering for $u_{1}$ and position-based triggering for $u_{2}$. Position-based triggering was used for $u_{2}$ because it offered superior tracking performance over CAD-based triggering, as it was able to respond to cycle-to-cycle variability in the engine valve's return trajectory. CAD-based triggering was used for $u_{1}$ because it offered similar lift tracking performance to position-based triggering, with the additional benefit of allowing $u_{1}$ to be activated before the valve's position has moved above the sensor noise level. This facilitates lift capability lower than the approximately 4-mm limit observed with position-based triggering, down to approximately $2.2 \mathrm{~mm}$ (in the limit of triggering $u_{1}$ in advance of the three-way valve $\left.u_{3}\right)$. 


\section{Chapter 3}

\section{Design of Iterative Learning Controller}

\subsection{Review of Iterative Learning Control}

Iterative learning control (ILC) is a control concept based on the notion that, for systems which are to perform the same desired act repeatedly, information from past executions (also referred to as runs, passes, trials, iterations, or cycles) can be leveraged to improve the system's performance. This is similar to the idea of "practice makes perfect" in humans, in which repetition of an action leads to improved execution of that action.

The idea of ILC is similar to that of repetitive control, with the important distinction that ILC is used for discontinuous operation, whereas repetitive control is used for continuous operation. That is, in ILC, the system is allowed to return to the same initial conditions (or initial conditions within some ball of uncertainty about the nominal initial conditions) between each run. This is often interpreted as a reset-and-rest action. One example of this is a fully-flexible valve actuation system, such as that described in Chapter 2 the system will execute a valve event, in which the engine valve opens to some desired lift and closes after a desired amount of time. The valve then waits for approximately three-fourths of the engine's cycle (540 CAD) at the seated, stationary position before it executes another valve event; the valve thus starts from the same initial conditions each time. Conversely, in repetitive control, each run immediately follows the run before, with the initial conditions of the $n^{\text {th }}$ run equal to the final conditions of the $(n-1)^{\text {st }}$ run. The mathematical approaches to these two control methodologies are consequently different from each other, but the idea of achieving convergence to a repeating desired trajectory using information from past cycles is a commonality between the two. 
The term ILC was first coined by Arimoto, et al. in a 1984 paper [15] showing its application to a robot manipulator. This is a common application of ILC, due to the repetitious motion many robots (for example, those that work on assembly lines) execute. Arimoto's controller was of the form

$$
u_{i}(t)=u_{i-1}(t)+L \dot{e}_{i-1}(t),
$$

where $u$ is the system input, $L$ is the learning gain (which may be a matrix, depending on the dimensionality of $u$ and $e$, and may also be a function of time $t$ ), and $\dot{e}$ is the time derivative of tracking error. Subscripts $i$ and $i-1$ indicate the current and previous iteration, respectively, and $t$ represents time (either continuous or discrete), which ranges from 0 to $T$ (the length of the iteration) during each iteration. The time derivative of the error signal from the previous cycle is thus multiplied by a gain and added point-wise to the input signal from the previous cycle, giving the input signal for the current cycle. This learning law is often referred to as "Arimoto-type" or "D-type" [16], the latter due to its use of the time-derivative of the error.

The learning algorithm in Eq. (3.1) guarantees error convergence $\lim _{i \rightarrow \infty} e_{i}=0$ when applied to a linear, time-invariant, continuous-time system with state-space representation $\{A, B$, $C, D\}$ as long as the matrix product $C B$ is non-singular, some initial conditions requirements are satisfied, and $\|I-C B L\|_{i}<1$ (here, subscript $i$ denotes the induced operator norm) [15] 16, 17. Note that this convergence criterion does not include the system's $A$ matrix, implying that this is a useful control form for systems in which the $A$ matrix is uncertain.

Another learning control law, the "P-type" (so called because it uses the error signal, rather than its time derivative), takes the form

$$
u_{i}(t)=u_{i-1}(t)+L e_{i-1}(t) .
$$

Note that, somewhat confusingly, that algorithms given in Eqs. (3.1) and (3.2) are both integral in nature in the iteration (or $i$ ) direction, although they are derivative and proportional, respectively, in the time direction.

Proportional and derivative actions in the iteration direction are also possible in what is often called "higher-order" ILC [18], in which the errors from multiple previous iterations are used. A general equation for higher-order ILC is given in Eq. (3.3): 


$$
u_{i}(t)=u_{i-1}(t)+\sum_{k=0}^{N} L_{k} e_{i-k}(t),
$$

where $N$ is the order of the ILC and $L_{k}$ is the learning gain on the $(i-k)^{\text {th }}$ error. This learning law also introduces another possibility in ILC: the use of current-iteration error. Clearly, when $k=0$ in the summation, the current $\left(i^{\text {th }}\right)$ error is used. This is similar to combining a traditional feedback controller with ILC. This structure is useful in that is allows the ILC to reject repeating disturbances (which occur each iteration), while allowing the feedback controller to reject nonrepeating disturbances [19].

Due to the nature of ILC, which utilizes information from past iterations, it is possible to implement what is sometimes referred to as "non-causal" learning [16, 19]. A learning algorithm is defined as "causal" if $u_{i}(t)$ depends only on $u_{i-k}(h)$ and $e_{i-k}(h)$ for $k \geq 0$ and $h \leq t$, and non-causal otherwise. Thus, to construct the input for the current cycle at a given moment in time $t$, a non-causal learning algorithm is allowed to utilize information from times later than $t$ in past cycles. Unlike the traditional definition of non-causality, a non-causal learning algorithm is implementable in practice, since this "future" information is available, because the previous cycles have already completed. A non-causal learning algorithm is thus able to pre-emptively respond to repeating disturbances, because it is able to "see" past the current time horizon $t$ when planning the current output $u_{i}(t)$.

As discussed in [19, 20], some ILC algorithms take the form

$$
u_{i}(t)=Q\left[u_{i-1}(t)+L e_{i-1}(t)\right],
$$

where $Q$ is called the Q-filter. This filter can act to select the frequency range over which learning is carried out; for example, if $Q$ were a low-pass filter, it would allow learning on low-frequency components of the error (e.g., long-term drift) while blocking learning on highfrequency components (e.g., sensor noise, from which it is not profitable to learn, as it is a non-repeating disturbance). [17, 19] present convergence criteria which help guide the design of $Q$ and $L$ for this general type of ILC.

Another type of iterative learning control is known as "point-to-point", in which a terminal error measurement $e_{i-1}(T)$ is made and is then used to modify the input signal $u_{i}(t)$. One example of this is given in [18] to control a rapid termal processing chemical vapor deposition 
(RTPCVD) process carried out on silicon wafers. Due to the nature of the RTPCVD, making in situ measurements of deposition thickness and wafer temperature are impractical in a production setting. It is, however, possible to measure the terminal deposition thickness (i.e., the thickness of the deposited film at the end of the process), which is the primary process output of interest. By representing the control signal (in this case, the lamp power) as a linear combination of a predetermined piecewise continuous functional basis, the control signal for each iteration can be calculated by using the terminal error from the previous iteration to update the coefficient vector, rather than using an entire error signal. Another example of this type of control is given in [21], in which the final positioning error of a car-like robot is used to update the steering and velocity inputs to drive it to a desired final location over a number of iterations.

This point-to-point ILC concept is germane to the current system to be controlled; recall that the FFVA system with IFS described in Chapter 2 is structured such that it does not track a precise desired valve profile; rather, it can alter the valve profile's timing, lift, duration, and seating velocity by changing the triggering timings of the two-state valves $\{1\},\{2\}$, and $\{3\}$, which affect the engagement of the hydro-mechanical feedback loop. The precise trajectory of the valve - which is less important than lift, timing, and duration from the perspective of engine control - is determined by these triggering timings and by the design of the IFS. This enables the simplification of external controls, but also means that the tracking error over the entire valve profile is not available; instead, valve profile parameters such as timing, duration, lift, and seating velocity, which are scalars, can be measured during each valve event and compared with desired (scalar) values.

However, the current control problem differs from the point-to-point ILC concept in that the inputs to the current system are also scalars rather than time signals for each iteration; that is, the external control inputs to the FFVA system with IFS are the on- and off-triggering timings for the three two-state valves $\{1\},\{2\}$, and $\{3\}$, which change only once per cycle, whereas the control inputs to the systems in [18 21] are time signals going from $0 \leq t \leq T$ for each iteration, as is more common in ILC. In other words, in the present system, inputs $u_{i}$, outputs $y_{i}$, and errors $e_{i}$ are scalars for each iteration; they are functions of iteration only and not of both iteration and time within each iteration (compare, for example, the notation $u_{i}(t)$ as used in Eqs. (3.1)-(3.4).

The desired output $y_{d}$ need not be constant each iteration; rather, as shown in [18 [19], it is sufficient if the rate at which $y_{d, i}$ changes with iteration $i$ is sufficiently small. This is a key 
point for the current control problem, as the desired operation of the engine valve will, in fact, change with engine operating condition; if it did not, it would no longer possess the flexibility that makes an FFVA system desireable. It will be seen later in this chapter that the present controller further alleviates this requirement by calculating error as $e_{i-1}=y_{d, i}-y_{i-1}$; that is, the error $e_{i-1}$ used in modifying the input for the current $\left(i^{t h}\right)$ iteration (as seen, for example in Eq. (3.2) is calculated using the actual output from the previous iteration and the the desired output from the current, rather than previous, iteration. This allows the ILC to pre-emptively modify the current iteration's input from the previous iteration's input in order to reach the desired output for the current iteration.

Additional information about ILC, including extensive literature surveys and theoretical discussions, can be found in [16, 17, 18, 19, 20, 22, 23]. Examples and demonstrations of applications of ILC can be found in [10, 15, 18, 19, 21].

\subsection{Control Overview}

An iterative learning controller (ILC) was designed to increase the system's robustness and tracking performance. Since the behavior of the plant when the IFS is active is fixed by design, the controller can affect the output only by altering the state of the plant when the hydromechanical feedback is activated. Effectively, the external controller sets the times at which the IFS becomes active, thus setting the initial conditions from which the internal feedback loop will operate. The present external controller is therefore an iterative learning controller for initial conditions of the fixed hydro-mechanical internal feedback mechanism.

Fig. 3.1 shows a block diagram of the proposed ILC architecture in which the complete dynamical model of the plant, including the valve actuator and the internal feedback spool valve, is presented as derived in [14]. The states $x_{1}, \ldots, x_{9}$ correspond to the actuator position and velocity, pressures in the actuator chambers $a, a_{1}, a_{2}$, spool position and velocity, and the pressures in the spool valve chambers $s_{1}$ and $s_{2}$, respectively. $M_{a}$ and $M_{s}$ are the masses of the actuator and the spool, respectively. $A_{a}, A_{a_{1}}, A_{a_{2}}, A_{s_{1}}, A_{s_{2}}$ are the cross-sectional areas of the various chambers in the actuator and the spool valve as shown in Fig. 2.1. $F_{p r e}, K_{a}$, $K_{s}, b_{a}$ and $b_{s}$ are the actuator preload force, spring stiffness, and damping associated with the actuator and the spool. The $x^{*}$ s correspond to the clearances in the various chambers. $A_{\text {spool }}$ is the instantaneous orifice area across the spool valve. The $Q$ s refer to the flow rates between 
various chamber as shown in Fig. 2.1 and are calculated using the orifice equation. A detailed description of the mathematical model, design parameters, and analysis of the internal feedback mechanism is presented in [14].

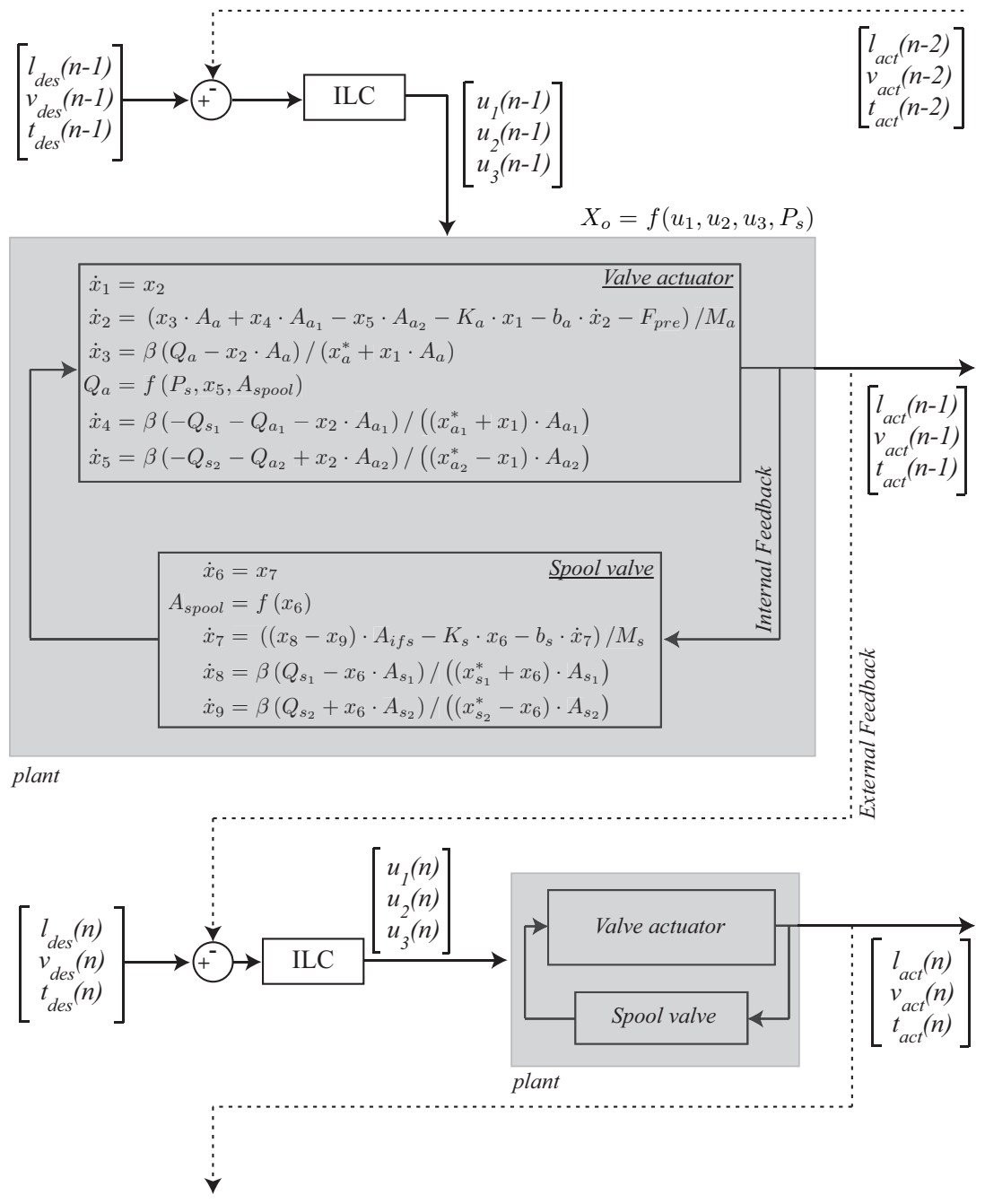

Figure 3.1: Block diagram of the proposed iterative learning controller 

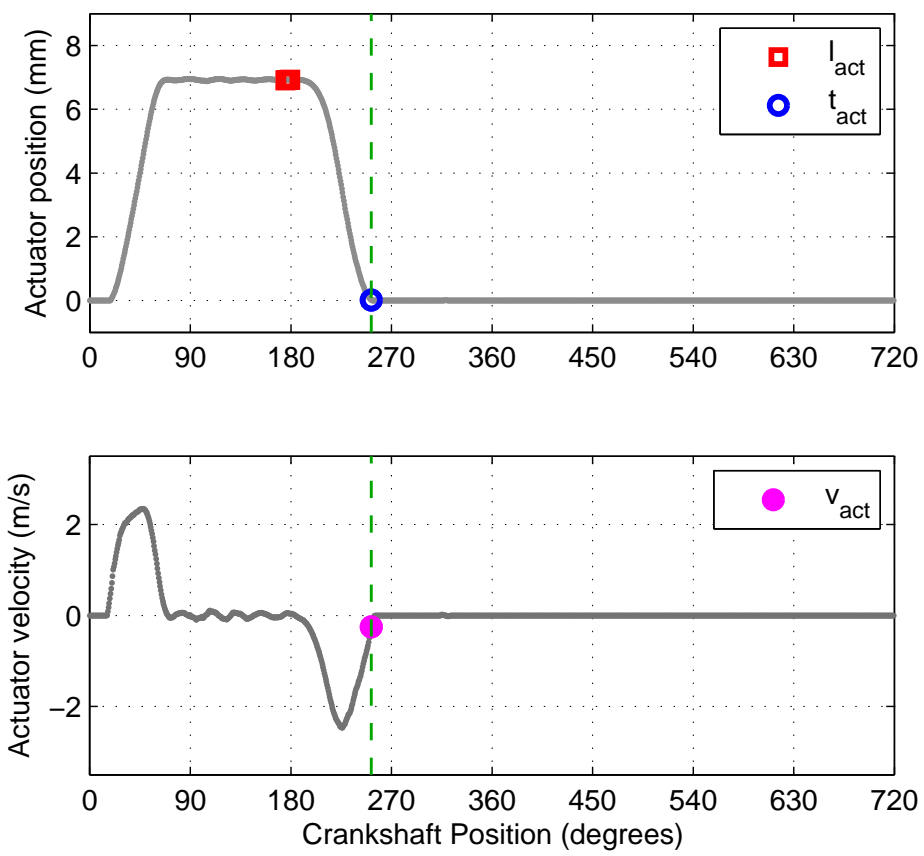

Figure 3.2: Valve event performance parameters for a given cycle

The ILC affects the performance of the system by calculating the triggering timings $u_{1}, u_{2}$, and $u_{3}$ for the three valves during engine valve opening and closing, which sets the initial conditions for all the nine states. The outputs of the plant (lift, closing time, and seating velocity) are then calculated at the end of each cycle. Fig. 3.2 shows a typical valve position and velocity trace and the corresponding valve event performance parameters. This output is used by the ILC to adjust the control input for the subsequent cycle to achieve the desired performance.

\subsection{Lift controller}

Lift is calculated by averaging the actuator's position over the $1.5 \mathrm{CAD}$ prior to turning off the three-way valve as shown in Fig. 3.2 This averaging makes the lift measurement more robust to sensor noise. A proportional-type ILC as shown in Eq. (3.5) is implemented for lift tracking. 


$$
u_{1}(n)=u_{1}(n-1) \frac{\omega_{e}(n)}{\omega_{e}(n-1)}+K_{1} \frac{\omega_{e}(n)}{\omega_{e, r e f}}\left[l_{\text {des }}(n)-l_{\text {act }}(n-1)\right],
$$

where $u_{1}$ is the time (in CAD after the opening of the three-way valve) at which on-off valve $\{1\}$ is closed, $\omega_{e}$ is the engine speed (in revolutions per minute [RPM]), $K_{1}$ is the proportional learning gain, $\omega_{e, r e f}$ is the reference engine speed at which the gain was calibrated (in this case, $2000 \mathrm{RPM}$ ) and $l$ is the lift (both desired and actual). The indices $n$ and $n-1$ are used to represent the current and previous cycles, respectively. Note that the desired lift for the current cycle and the actual lift for the previous cycle are used to calculate the error term. This is somewhat atypical, and allows the elimination of most lag from the lift tracking. It will be seen that a similar strategy is used on the seating-side controller described in the next section. Also note that the $\omega_{e}$ terms scale both $u_{1}(n-1)$ and $K_{1}$ with engine speed to ensure proper behavior (since the length of one CAD scales with engine speed). $K_{1}$ is chosen as $\left[\Delta l_{\text {act }} / \Delta u_{1}\right]^{-1} \mathrm{CAD} / \mathrm{mm}$ where $\left[\Delta l_{\text {act }} / \Delta u_{1}\right]$ is the slope of the line approximating the data from open-loop tests relating the triggering timing of $u_{1}$ and the valve lift $l_{\text {act }}$ at the reference engine speed. It would also be possible to update this gain in real-time to compensate for changes in the supply pressure. Fig. 3.3 shows the performance of the controller for tracking a step change in lift for different values of the learning gain $K_{1}$.

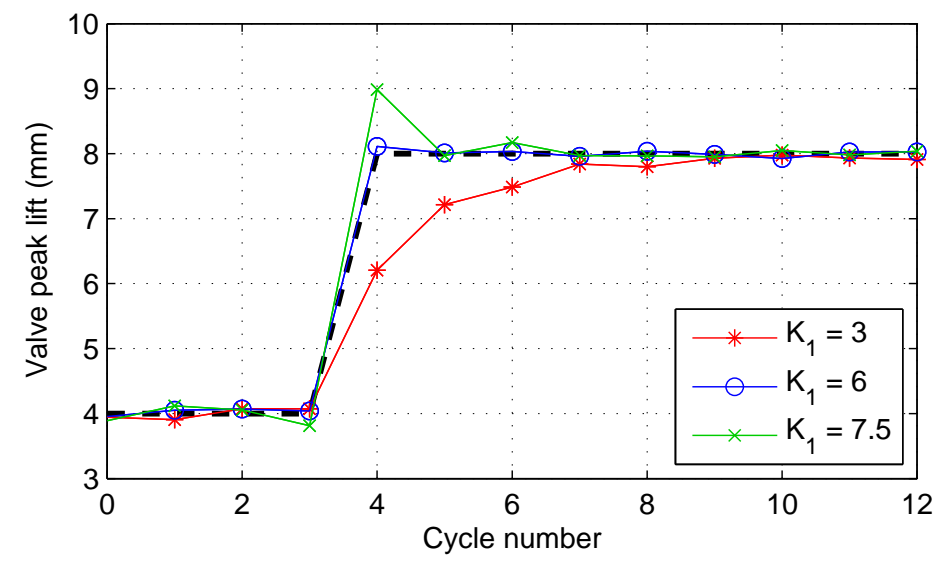

Figure 3.3: Transient tracking performance for a step change in lift with different gain values 


\subsection{Seating controller}

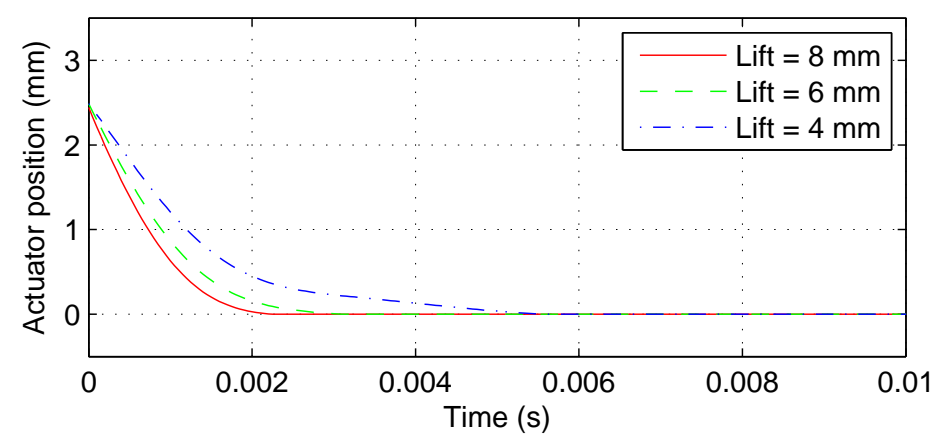

(a)

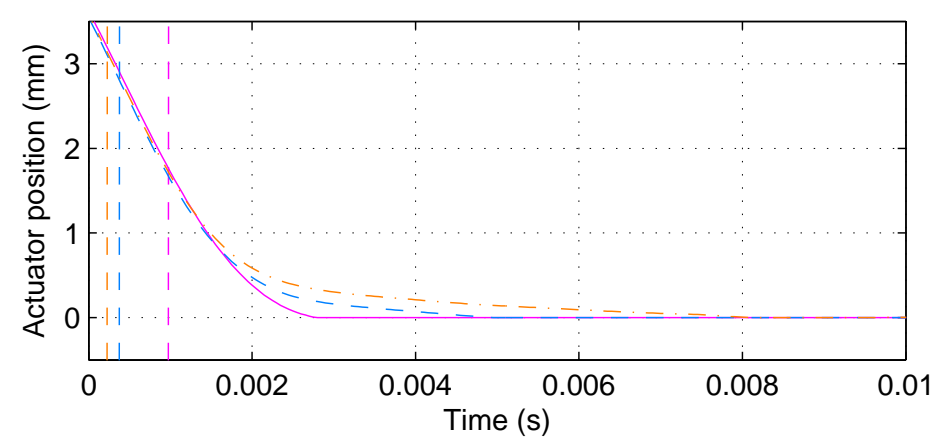

(b)

Figure 3.4: Effect of initial conditions on the system trajectory

The valve is considered to be seated at the instant when the actuator crosses $0.1 \mathrm{~mm}$ going downward. This slight offset is used to ensure that the sensor noise does not affect the calculation of closing time. The crankshaft position (in CAD) at the time when this crossing occurs is reported as the closing time. The actuator velocity is calculated by numerically differentiating the position data. The actuator velocity corresponding to the closing time is reported as the seating velocity. This is illustrated in Fig. 3.2

The initial conditions of the IFS during valve closing will be disturbed by changes in valve lift. As the lift increases, the actuator velocity for the same triggering position will increase. This changing actuator velocity along with the on-off valve delay time will affect the seating behavior of the system. This can be seen in Fig. 3.4 a), where the valves are triggered at 
$2.55 \mathrm{~mm}$ for all cases, returning from varying lifts. Hence, the on-off valve timing needs to be adjusted to compensate for these variations to ensure desired seating behavior. The three-way valve will also need to be adjusted to compensate for the varying amounts of time the engine valve will require to return from different lifts. Fig. 3.4 (b) shows the effect of varying triggering timing when returning from a constant lift (in this case, $6 \mathrm{~mm}$ ). It can be seen that the valve takes a longer time to seat at lower seating velocities. The three-way valve off triggering timing can be used to compensate for this effect as well.

The system exhibits an inherent tradeoff between seating velocity and variability in closing time. It can be seen in Fig. 3.5 that the variability in closing time increases as the seating velocity decreases and as lift increases. In general, the seating velocity is allowed to increase with engine speed, and since high lifts are required only for high engine speeds, the system will never operate in the high-variability regions on the plot. There is also an optimal point at each operating condition at which the seating velocity is as low as possible while maintaining the closing time variability near the system's inherent limit.

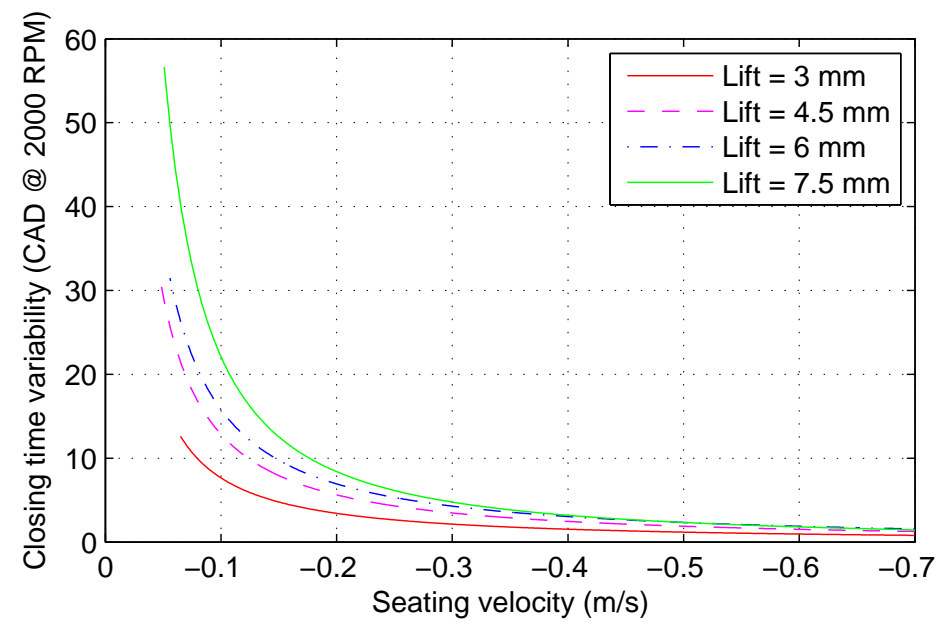

Figure 3.5: Tradeoff between closing time variability to seating velocity

To identify that optimal operating point, an auxiliary variable $\left(v_{a u x}\right)$ for the desired seating velocity is calculated online and updated using the following equation: 


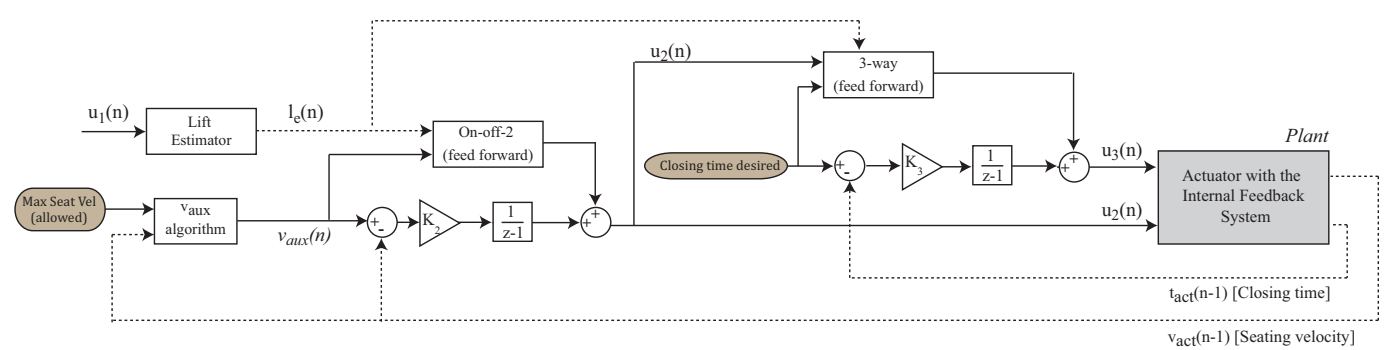

Figure 3.6: Block diagram of the feed-forward + feedback controller for seating behavior

$$
v_{\text {aux }}(n)=v_{\text {max }, \text { des }}(n)+\frac{1}{20} \sum_{k=1}^{20}\left|v_{\text {aux }}(n-k)-v_{a c t}(n-k)\right|
$$

where $v_{\text {max,des }}$ is the upper bound on seating velocity, $v_{a c t}$ is the actual observed seating velocity, $n$ is again the index corresponding to the current cycle, and $k$ is an index of summation. Higher seating variability will tend to increase the value of $v_{a u x}$, while any velocities greater in magnitude than the desired threshold will act to decrease it. The value for $k$ was chosen as 10 , to minimize oscillation in $v_{\text {aux }}$ while having the best possible transient response. Please note that all seating velocity values are negative by convention, as seen on the $\mathrm{x}$-axis of Fig. 3.5

This algortihm looks back at the mean magnitude of seating velocity error over the past 20 cycles. This mean error magnitude can be viewed as an estimate of the one-sided variability for seating velocity tracking. The algorithms takes this variability and adds it to the current seating velocity bound (which is negative in sign, as discussed above). This is the the value of $v_{\text {aux }}$ for the current cycle, which is designed to set the mean seating velocity over several cycles such that the seating velocities which are highest in magnitude (i.e., most negative), fall mostly below the desired bound. The seating controller discussed below will then attempt to track this value of $v_{a u x}$. This control architecture is more practical since the maximum velocity threshold can be set for each lift and/or engine speed to satisfy noise and wear concerns. 

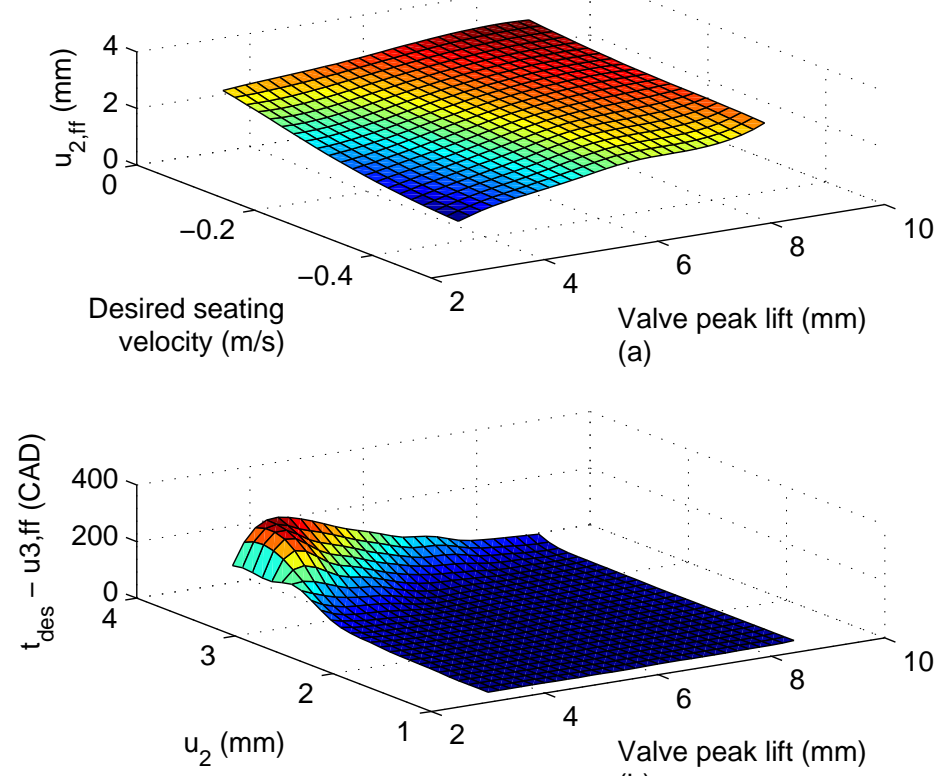

(b)

Figure 3.7: Calibration surfaces for the feed-forward components of the controller

Fig. 3.6 shows the block diagram of the proposed seating controller that contains both feedforward and feedback terms to compensate for the variation in initial conditions for the seatingside IFS due to lift variation and to account for the coupled effect of the closing time and seating velocity between the on-off and the three-way valves. The control inputs are calculated using the following equations:

$$
\begin{aligned}
u_{2}(n) & =u_{2, f b}(n)+u_{2, f f}(n) \\
u_{2, f b}(n) & =u_{2, f b}(n-1)+K_{2} \cdot\left[v_{a u x}(n)-v_{a c t}(n-1)\right] \\
u_{2, f f}(n) & =\mathcal{F F}_{2}\left(l_{e}, v_{a u x}\right) \\
u_{3}(n) & =u_{3, f b}(n)+u_{3, f f}(n) \\
u_{3, f b}(n) & =u_{3, f b}(n-1)+K_{3} \cdot\left[t_{d e s}(n)-t_{a c t}(n-1)\right] \\
u_{3, f f}(n) & =t_{\text {des }}(n)-\mathcal{F F}_{3}\left(l_{e}, u_{2}(n)\right),
\end{aligned}
$$


where $u_{2}$ is the or lift (in mm) at which on-off valve $\{2\}$ is closed, $u_{3}$ is the time (in CAD) at which the three way valve $\{3\}$ is closed, $u_{2, f b}$ and $u_{2, f f}$ are the feedback and feed-forward portions of the control input for on-off valve $\{2\}, u_{3, f b}$ and $u_{3, f f}$ are the feedback and feed-forward portions of the control input for the three-way valve $\{3\}, K_{2}$ and $K_{3}$ are the corresponding proportional learning gains. $K_{2}$ is chosen experimentally to enable $v_{\text {act }}$ to effectively track $v_{\text {aux }}$. Since the relationship between $u_{3}$ and $t_{\text {act }}$ is one-to-one, $K_{3}$ can be set to $1 \mathrm{CAD} / \mathrm{CAD}$ to ensure adequate tracking. $\mathcal{F} \mathcal{F}(\cdot)$ is a surface mapping the inputs to the feed-forward output, $l_{e}(n)$ is an approximation of the lift for the current $\left(n^{t h}\right)$ cycle based on $u_{1}(n)$ as calculated by Eq. (3.5), and $v$ and $t$ are the performance parameters (desired and actual) seating velocity and closing time, respectively. Again, the indices $n$ and $n-1$ are used to represent the current and previous cycles, respectively.

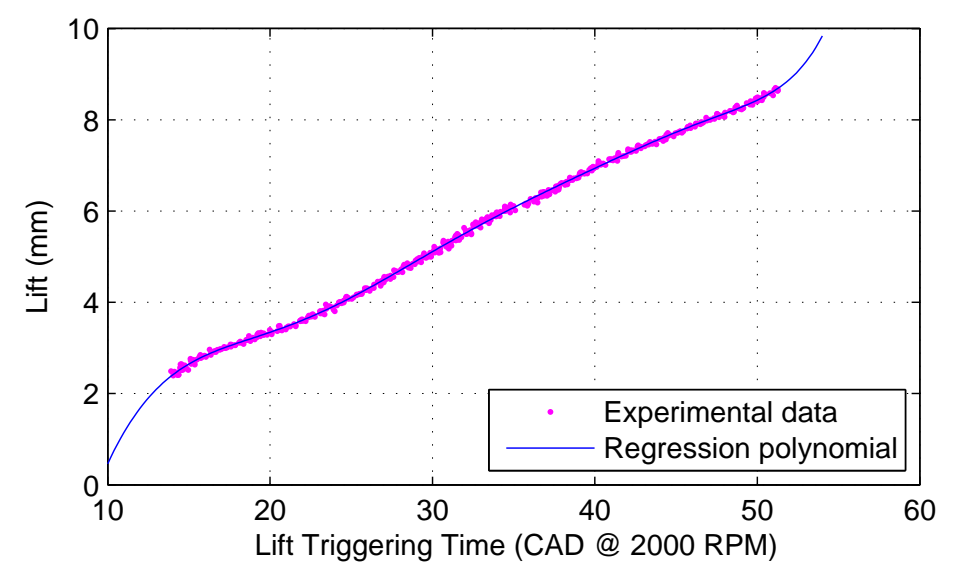

Figure 3.8: Experimental data and best-fit curve for lift estimation equation

The feed-forward surfaces for lift-based triggering of $u_{2}\left(\mathcal{F F}_{2}\right)$ and CAD-based triggering of $u_{3}\left(\mathcal{F F}_{3}\right)$ are shown in Fig. 3.7 a) and (b) respectively. These feed-forward surfaces were obtained by performing feedback-only steady-state set-point tracking experiments for different lifts and desired seating velocities, and using the resulting data to build look-up tables of $u_{2}$ and $u_{3} . \mathcal{F F}_{3}$ has been calibrated at 2000 RPM. For other engine speeds (at which each CAD represents a different amount of time), it can be scaled appropriately.

The lift estimation equation is an eighth-order polynomial obtained by performing a leastsquares regression on experimental data of valve lift $l_{\text {act }}$ versus valve $\{1\}$ triggering time $u_{1}$ 
(in CAD at 2000 RPM). These data and the lift-estimator curve are shown in Fig. 3.8. In the controller, the input $u_{1}$ is scaled from the current engine speed to 2000 RPM to ensure that only one such estimation curve is needed. 


\section{Chapter 4}

\section{Review of Non-throttled Engine Load Control}

One main source of efficiency loss in the spark-ignition (SI) ICE is pumping loss, caused by how its load (energy output) is typically controlled. An SI engine usually must operate near chemically-correct (stoichiometric) air-fuel ratios due to combustion stability and emissions requirements. Decreasing the energy output of an SI engine, which is necessary in mobile applications due to their varying power demand, requires decreasing the amount of fuel introduced into the cylinder for each engine cycle, and thus requires decreasing the amount of air introduced into the cylinder as well (to maintain near-stoichiometric operation). In the vast majority of such engines, this latter point is accomplished by the use of a throttle valve, which decreases the pressure, and thus density, of the air introduced to the engine. This, in turn, causes pumping losses, because the engine must accept fresh charge at a lower pressure, and then reject exhaust at approximately atmospheric pressure. This pumping loss is shown as the shaded area in the idealized pressure-volume indicator diagram, zoomed in to focus on the exhaust and intake strokes, presented in Fig.4.1.

Controlling the load of the engine without using the throttle valve could significantly reduce this pumping loss, as the intake pressure would be very nearly equal to the exhaust pressure. Reducing the pumping loss would lead to an increase in the engine's thermal efficiency (defined as the useful work output of the engine divided by the energy content of the fuel used to produce that work). This concept is referred to as non-throttled engine load control (NTELC). Several 


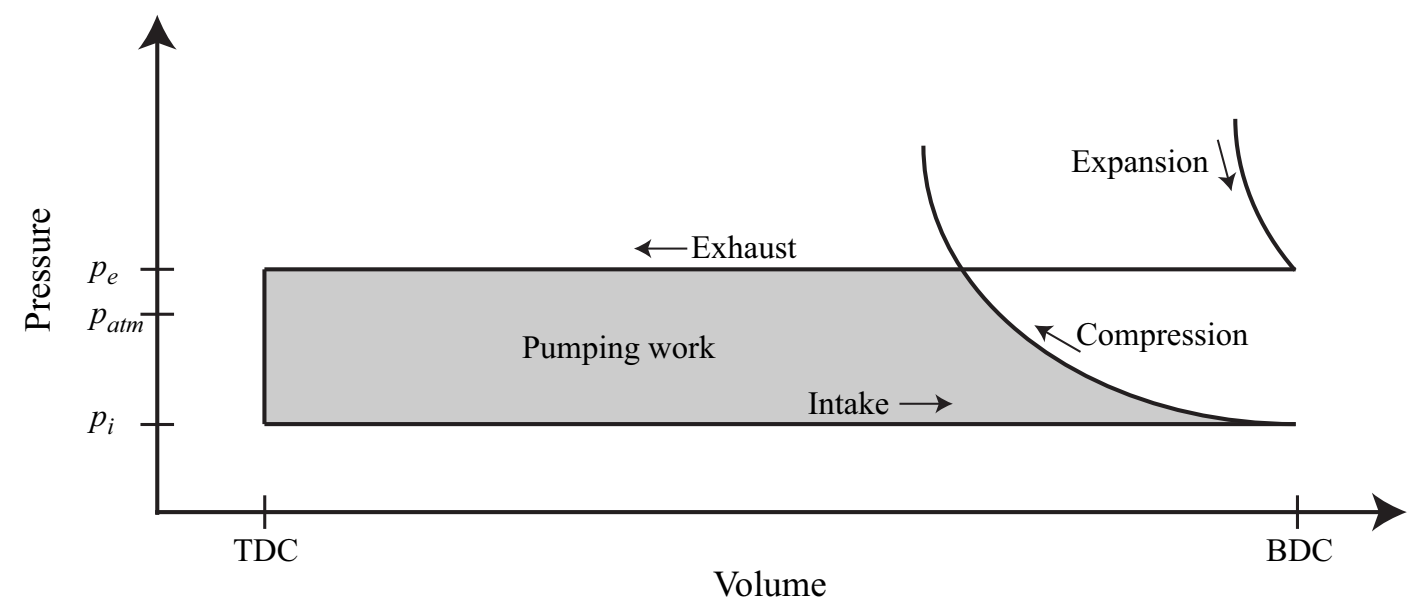

Figure 4.1: Schematic indicator diagram showing pumping work (shaded). Here, TDC and BDC refer to the piston's top- and bottom-dead center positions, respectively, $p_{e}$ and $p_{i}$ refer to the exhaust and intake pressures, respectively, and $p_{a t m}$ is atmospheric pressure. Note that $p_{i}$ is significantly lower than $p_{a t m}$

implementations of NTELC have been proposed. A brief survey of these methods follows.

\subsection{NTELC via Lean-Burn Capability}

One way to reduce pumping losses is to alleviate the requirement that a stoichiometric air-fuel ratio be maintained. This would allow the intake of a full cylinder volume of near-ambientdensity air, adjusting the amount of fuel introduced to the cylinder to control the load of the engine. As noted before, this causes several problems. One major issue is that the spark plug will not readily ignite the air-fuel mixture when the air-fuel ratio is lean, as under low-load conditions.

Modern diesel engines circumvent this problem by compressing the air and then using direct injection to spray fuel into the cylinder, where high temperatures ensure autoignition of the fuel. This combustion, however, is not well-mixed and contains fuel-rich regions, which leads to higher particulate emissions, and takes place at high temperature, which leads to higher oxides of nitrogen $\left(\mathrm{NO}_{\mathrm{x}}\right)$ emissions. These require expensive aftertreatment systems to allow 
the engines to operate within environmental regulations. That having been said, modern diesel engines are more fuel-efficient than their SI counterparts, in part due to the high compression/expansion ratios used (raising the theoretical efficiency of the diesel engine), and in part due to the lack of significant pumping losses [24].

Stratified-charge SI engines use appropriately timed direct injection to add the desired amount of fuel to the cylinder in such a way that a stoichiometric air-fuel mixture is formed near the spark plug, where it can be ignited, while the rest of the cylinder contains a very lean mixture consisting mostly of air and/or residual exhaust. This again reduces the need for a throttle, and has been introduced in several production automobiles. These engines typically still use a throttle for some load control, however, as the range permitted by stratified charge operation is somewhat limited [24]. In addition, the excess air in the exhaust can cause aftertreatment challenges [3].

A hybrid between SI and diesel combustion is called homogeneous-charge compression ignition (HCCI). This, again, varies the load of the engine by varying the amount of fuel introduced to the cylinder, while keeping the amount of air relatively constant. Similarly to diesel, HCCI ignites this lean mixture by compressing it to its autoignition point. HCCI circumvents the emissions problems of diesel engines by premixing the fuel and air before and during compression. This ensures relatively cool combustion, with few fuel-rich pockets, thus ensuring $\mathrm{NO}_{\mathrm{x}}$ and low particulate emissions. However, the control of combustion onset is much more difficult than in either an SI engine, where it is controlled by spark timing, or in a diesel engine, where it is controlled by the fuel injection timing. This hurdle has so far precluded the production implementation of an HCCI engine, but it nonetheless shows great promise [8].

A fourth lean-burn technology is referred to as jet ignition. In jet ignition engines, a lean air-fuel mixture in the cylinder is ignited by a jet of flame. This flame jet is produced in a small pre-chamber containing a slightly rich, easily-ignitable air-fuel mixture that is ignited by a spark plug in the pre-chamber. This flame then jets into the main combustion chamber, allowing the ignition of very lean overall air-fuel mixtures. Efficiency (and thus fuel consumption) benefits of up to $10-15 \%$ and a wide range of achievable loads are claimed [25]. 


\subsection{NTELC via Intake Regulation}

Another way to realize NTELC is to maintain a stoichiometric air-fuel ratio while keeping the intake charge near atmospheric pressure, regulating the amount of air introduced to the cylinder by cutting off the intake completely at an appropriate point. This traps the desired amount of air in the cylinder. This, in turn, varies the net amount of compression the air undergoes, thus varying the effective compression ratio while maintaining the expansion ratio as the geometric compression ratio of the engine. This concept is thus similar to the Atkinson/Miller cycle, and is sometimes referred to as such [26]. When compared to the Atkinson/Miller cycle, this system possesses the advantage that it is able to vary the effective compression ratio (and the amount of fresh charge), allowing high specific output comparable to a traditional Otto-cycle SI engine at high load, while maintaining a high efficiency at light load.

Several methods to close off the intake have been investigated. An additional rotary [26] or poppet [27] valve can be installed in each intake runner and shut to cut off intake air. This has the advantage of allowing a conventional cam strategy for the engine's existing intake valves, and allows more flexibility in actuation for the secondary valves vis-à-vis controlling the load with the existing intake valves. This system is thus easily compatible with existing engine architecture. However, an additional valve is required for each intake runner of the engine, which increases mechanical complexity. The volume of air trapped between the secondary and primary valves causes a reduction in efficiency of, in one example, 20-45\%. Even so, fuel savings of around 5\% at part load and $15 \%$ at idle are projected [27].

The majority of intake-cutoff NTELC implementations, however, utilize variable valve actuation to control the intake valve to regulate the amount of air introduced into the cylinder. J.H. Tuttle of General Motors published two seminal, much-cited papers in the 1980s. In the first of these [28], he investigated using late intake-valve closing (LIVC) as a load control methodology. In LIVC, the intake valve is kept open past bottom dead center (BDC) of the intake stroke. As the piston begins to return toward the top dead center (TDC) position, it will push out some fresh charge back through the intake valve into the intake manifold. When the intake valve closes, it will trap an amount of fresh charge in the cylinder related to the volume of the cylinder when the intake valve closes. Tuttle reported fuel savings of up to $6.5 \%$, and the ability to achieve a $56 \%$ decrease in load by keeping the intake valve open 96 additional CAD. However, retarding the closing of the intake valve by much more than this produced a decrease in 
the thermal efficiency of the engine due to higher burning-time losses, so a throttle was deemed necessary to achieve load reductions of higher than $56 \%$ [28].

The second of Tuttle's papers [29] covers early intake-valve closing (EIVC), in which the intake valve is closed before the piston reaches BDC of the intake stroke. The amount of fresh charge in the cylinder is related to the volume of the cylinder at which the intake valve is closed. This poses a slight inherent theoretical advantage over LIVC in that pumping losses will be encountered only drawing fresh charge into the cylinder past the intake valve, whereas these valve flow losses are encountered both in drawing a large volume of fresh charge into the cylinder and in expelling some of that fresh charge back out past the intake valve. Tuttle shows that over $200 \mathrm{CAD}$ of range in intake valve closing timing is needed to reduce the load to $20 \%$ of maximum, deemed enough to do away with the throttle. A possible disadvantage of this method is the potentially high valve accelerations necessary to achieve sufficiently short valve durations, especially at high engine speeds. This, combined with the wide range in intake valve closing timing necessary, poses some actuation challenges, but fuel economy improvements of up to $10 \%$ are observed, with improvements up to $7 \%$ in a typical road-load scenario. Tuttle also claims that a lower idle speed is made possible, which opens an additional avenue to fuel savings [29].

In his papers, Tuttle used a series of specially-designed camshafts of fixed geometry to investigate the effects of changing load. To implement EIVC or LIVC in a production engine, a mechanism for varying the intake valve timing is needed. BMW's Valvetronic system utilizes simultaneous cam phasing (which changes the CAD at which peak intake valve lift is achieved) and continuously variable lift (which also changes valve duration, but not independently) to achieve NTELC, with a claimed fuel savings of up to $20 \%$ at low load, and approximately $10 \%$ overall [3]. The similar Uni-Valve system has demonstrated additional benefits from also varying the lift, duration, and phasing of the exhaust valve, which the authors claim can optimize in-cylinder turbulence to increase combustion stability even with high residual gas fractions [30].

Fiat's Multi-Air system, which uses a camshaft coupled to the intake valves through a hydraulic system, is even more flexible in its possible intake valve profiles. A high-tech, ethanolfueled direct-injection, turbocharged engine with Multi-Air has uses $40 \%$ less fuel energy in a simulation of the New European Driving Cycle than a conventional engine of similar power output. By itself, Multi-Air has a 10\% fuel consumption benefit on a gasoline engine, with 
savings of up to $15 \%$ at low loads [31].

The disadvantage to these cam-based variable valve actuation systems is that a high degree of mechanical complexity is required to grant flexibility to the inherently inflexible cam. In addition, achieving the high range of variability in intake valve profiles that is required for NTELC is difficult in such systems, and completely independent variation of valve timing, duration, and maximum lift has not yet been demonstrated in a cam-based framework. The solution is to eliminate the cam and use individual actuators on each engine valve. Such a system is referred to as "camless" or fully-flexible valve actuation (FFVA). Most FFVA implementations use either electro-mechanical [3], electro-pneumatic [32], or electro-hydraulic [12] actuation. [33] presents simulation results demonstrating the use of a model-based controller to determine valve event paramters for non-throttled load control of a camless engine. Expected average efficiency improvements with FFVA due to NTELC alone are expected to be around $11 \%$, fairly similar to the cam-based systems discussed above. However, the additional flexibility grated by FFVA can also enable many other operating benefits, as discussed in Chapter 1 


\section{Chapter 5}

\section{Vehicle Load Demand Analysis and Non-throttled Engine Load Control}

For an engine utilizing an FFVA for NTELC, the lack of a mechanical connection between the engine's crankshaft and valves, and the lack of a throttle valve, an interpretation from the driver's command (at the accelerator pedal) to the desired valve trajectory parameters is required. It is assumed in the following analysis that the desired acceleration is known a priori; in reality, it would have to be calibrated based on accelerator pedal position and vehicle operating conditions (vehicle speed, engine speed, etc.). This chapter will discuss a general procedure for determining the desired valve trajectory parameters. Fig. 5.1] shows the architecture of this NTELC via FFVA framework.

\begin{tabular}{|c|c|c|c|c|c|c|c|c|}
\hline $\begin{array}{l}\text { Driving } \\
\text { cycle }\end{array}$ & $v, a$ & $\begin{array}{l}\text { Vehicle Load } \\
\text { Analysis }\end{array}$ & $T E$ & $\begin{array}{l}\text { Engine Speed } \\
\text { and Load } \\
\text { Calculation }\end{array}$ & $\tau_{b}, \omega_{e}$ & $\begin{array}{c}\text { Required } \\
\text { Air Mass } \\
\text { Calculation }\end{array}$ & $m_{a, n}$ & $\begin{array}{c}\text { Valve Duration } \\
\text { and Lift } \\
\text { Calculation }\end{array}$ \\
\hline
\end{tabular}

Figure 5.1: Block diagram of NTELC via FFVA framework

Each block in Fig. 5.1 will be discussed in more detail in the following sections. As a realistic example of typical driver input, the Environmental Protection Agency's Federal Test Procedure (FTP) driving cycle [34] is used; it is $1875 \mathrm{~s}$ (31 minutes, 15 seconds) long, with a maximum speed of 56.7 miles per hour ( $\mathrm{mph}$ ) and a mean speed of $21.21 \mathrm{mph}$, and is intended to 
represent urban conditions. The FTP cycle is presented as a time-versus-speed trace, as shown in Fig. 5.2

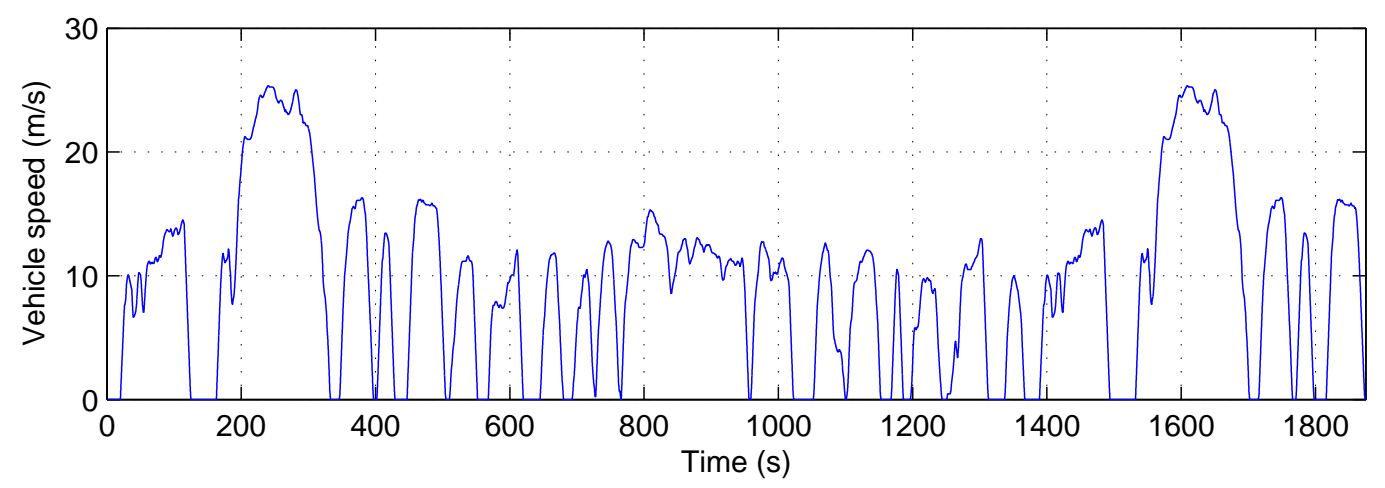

Figure 5.2: Plot of vehicle speed vs. time for the FTP cycle

\subsection{Vehicle Load Demand Analysis}

Vehicle load demand analysis consists of determining the required force (or torque) at the wheels for a vehicle at a particular driving condition. Vehicle load analysis has been investigated in [35, 36, 37]. In general, the force at a vehicle's wheels (often referred to as the tractive effort, or $T E$ ), consists of four components: $R R$, the rolling resistance; $W R$, the wind resistance (or aerodynamic drag); $G R$, the grade resistance (or force required to climb a grade against gravity); and $A R$ is the acceleration resistance (or inertial load). The formulae for $T E$ and for each of these components are given in Eq. (5.1) below:

$$
T E=\underbrace{K_{1} M_{v} g \cos (\theta)}_{R R}+\underbrace{\frac{1}{2} \rho_{a} C_{D} A_{f} v^{2}}_{W R}+\underbrace{M_{v} g \sin (\theta)}_{G R}+\underbrace{\left[M_{v}+\frac{J_{w}}{r_{r}^{2}}+\frac{J_{p} r_{f}^{2}}{r_{r}^{2}}+\left(J_{t}+J_{e}\right) \frac{r_{f}^{2} r_{t}^{2}}{r_{r}^{2}}\right]}_{A R} a,
$$

where $K_{1}$ is the dimensionless rolling resistance coefficient, $M_{v}$ is the vehicle mass, $g$ is the acceleration due to gravity, $\theta$ is the grade (the angle the road makes with the horizontal, with positive angle being an uphill slope), $\rho_{a}$ is the density of the atmosphere, $C_{D}$ is the drag coefficient of the vehicle, $A_{f}$ is the vehicle's frontal area, $v$ is the vehicle speed, $J_{w}, J_{p}, J_{t}$, and 
Table 5.1: Vehicle parameter values used in load demand analysis

\begin{tabular}{llll}
\hline \hline Parameter & Value $($ units $)$ & Parameter & Value (units) \\
\hline$K_{1}$ & $0.015[35, \mid 36]$ & $A F$ & 14.6 \\
$M_{v}$ & $1500(\mathrm{~kg})$ & $V_{d}$ & $2.0(\mathrm{~L})$ \\
$\rho_{a}$ & $1.204\left(\mathrm{~kg} / \mathrm{m}^{3}\right)$ & $p_{a}$ & $1.01325 \cdot 10^{5}(\mathrm{~Pa})$ \\
$C_{D}$ & 0.3 & $T_{a}$ & $293.15(\mathrm{~K})$ \\
$A_{f}$ & $2.35\left(\mathrm{~m}^{2}\right)$ & $p_{0}$ & $1.06 \cdot 10^{5}(\mathrm{~Pa})$ \\
$J_{e}, J_{t}, J_{p}, J_{w}$ & $0\left(\mathrm{~kg} \cdot \mathrm{m}^{2}\right)$ & $T_{0}$ & $1000(\mathrm{~K})$ \\
$r_{r}$ & $0.325(\mathrm{~m})$ & $c_{d}$ & 0.6 \\
$r_{f}$ & 3.37 & $R_{a}$ & $287.058(\mathrm{~J} / \mathrm{kg} \cdot \mathrm{K})$ \\
$\eta_{t}$ & $0.853[\mathbf{3 8} \mid \mathbf{3 9}]$ & $r_{c s}$ & 1.7 \\
$\eta_{f}$ & $0.961[36, \mid 37]$ & $s$ & $7.62 \cdot 10^{-2}(\mathrm{~m})$ \\
$K_{i, 0}$ & $140(\mathrm{RPM} / \sqrt{l b \cdot f t})[39]$ & $b$ & $9.14 \cdot 10^{-2}(\mathrm{~m})$ \\
$n$ & 4 & $r$ & 10.0 \\
$e_{c}$ & $4.4 \cdot 10^{7}(\mathrm{~J} / \mathrm{kg})$ & $n_{v}$ & 2 \\
$d_{v}$ & $3.29 \cdot 10^{-2}(\mathrm{~m})$ & $\beta$ & $45^{\circ}$ \\
$w$ & $1.5 \cdot 10^{-3}(\mathrm{~m})$ & $d$ & $2.99 \cdot 10^{-2}(\mathrm{~m})$ \\
$d_{s}$ & $6.3 \cdot 10^{-3}(\mathrm{~m})$ & & \\
\hline
\end{tabular}

$J_{e}$ are the rotational inertias of the wheels, propshaft, transmission, and engine, respectively, $r_{r}$ is the rolling radius of the wheels, $r_{f}$ and $r_{t}$ are the final-drive and transmission ratios, respectively, and $a$ is the vehicle acceleration. The four forward transmission ratios are given by $[2.393,1.450,1.000,0.677]$.

The above equations are used to calculate $T E$ every $0.02 \mathrm{~s}$ from the FTP cycle discussed above. The vehicle acceleration was calculated from numerically differentiating the FTP cycle data. Lacking any other information, the grade angle $\theta$ is assumed to be a constant zero, a reasonable approximation for urban driving in many cities. Thus the $G R$ term in Eq. (5.1) will be ignored for the rest of the analysis. An additional simplification was made in ignoring driveline inertia by setting $J_{w}, J_{p}, J_{t}$, and $J_{e}$ to zero; thus the acceleration resistance term in Eq. (5.1) reduces to $M_{v} a$. Other relevant vehicle parameters can be found in Table 5.1, with parameter meanings described throughout this chapter. In general, parameters were selected to reflect a typical modern compact to midsize car (C- to D-segment). The engine was selected as a typical 2.0-liter four-cylinder engine with four valves per cylinder and a maximum torque output of $200 \mathrm{~N} \cdot \mathrm{m}$. 


\subsection{Engine Speed and Load Calculation}

Once TE has been calculated, the operating point of the engine (speed and torque/load) must be calculated at each time step. The engine speed $\left(\omega_{e}\right)$ is related to the vehicle speed $(v)$ by Eq. (5.2), below.

$$
\omega_{e}=\frac{r_{f} r_{t}}{r_{r}} v
$$

Furthermore, the engine brake torque output $\left(\tau_{b}\right)$ is related to the force at the wheels (TE) by Eq. (5.3):

$$
\tau_{b}=\frac{r_{r}}{r_{f} r_{t} \eta_{t} \eta_{f}} T E
$$

Here, $\eta_{t}$ is the transmission efficiency and $\eta_{f}$ is the final-drive efficiency, i.e. the ratio between engine output power and the power applied at the wheels. Note that Eqs. 5.2 and (5.3) require the transmission ratio $r_{t}$, which will change as a function of driving condition, to calculate the engine speed and torque output. In fact, many automatic transmission shifting schedules operate using vehicle speed and percent throttle as inputs. An iterative method is used to determine the gear (and thus the transmission ratio) and the engine speed and load. As the FTP cycle begins at a vehicle speed of zero, the vehicle can be assumed to start in first gear. This assumption is used to calculate the engine speed and load for the first time step. These are then fed into an engine output map (shown in Fig. 5.3) to determine the required percent throttle to produce the required engine torque at the required engine speed. This percent throttle, along with the vehicle speed, is fed into transmission logic from a typical automatic transmission with four forward speeds, which determines the shift command (upshift, downshift, or stay in current gear) based on these inputs. Note that the percent throttle is calculated only for the purpose of determining gearshifts. This process is repeated at each time step, using the gear commanded in the previous time step to determine engine speed and torque, as well as the shift command for the current time step (which will be used in the next time step).

Gear shifts were assumed to be $0.7 \mathrm{~s}$ in duration. Specific gear shift mechanics are ignored; the transmission ratio is assumed to shift linearly between gears over this time interval. This iterative solution method has the possibility to give rise to some errors, but because the simulation time step $(0.02 \mathrm{~s})$ is significantly smaller than both the gear shift duration $(0.7 \mathrm{~s})$ and 


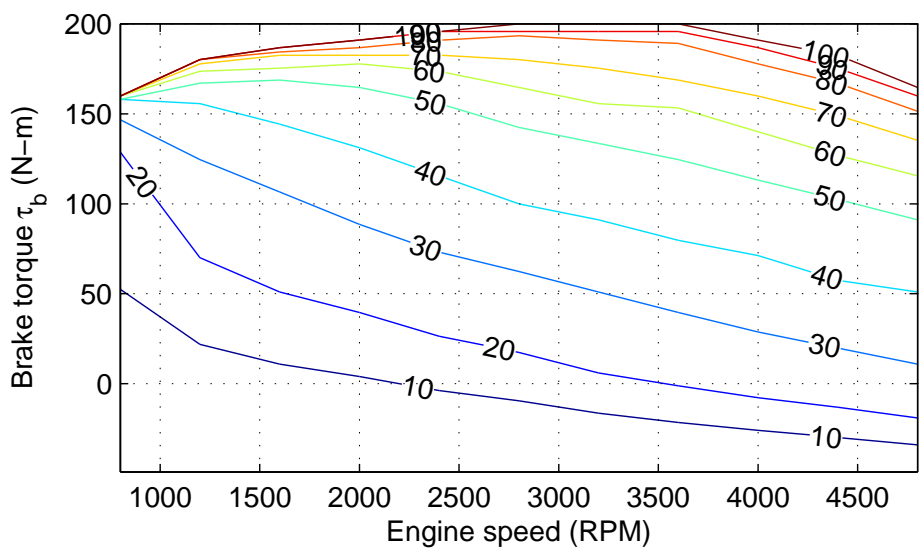

Figure 5.3: Engine output map used in simulation. Contours represent lines with constant percent throttle as labeled

the time difference between consecutive points in the FTP specification $(0.1 \mathrm{~s})$, such errors are expected to be insignificant.

Engine speed is not allowed to go below the idle set-point, here assumed to be 600 RPM. It is assumed that vehicle speeds requiring lower engine speeds will either lead to a downshift, or that the transmission's torque converter will begin to slip, allowing the engine to maintain its minimum speed. At other conditions, the convertor is assumed to be locked so that the output speed of the engine is equal to the input speed to the transmission's planetary gear set.

Similarly, the engine torque is not allowed to go below an assumed minimum torque required to overcome torque converter drag at idle. At idle, the maximum torque input possible to the stalled torque converter before it begins to move is determined by Eq. (5.4) [36]:

$$
\tau_{b}=\left(\frac{\omega_{e}}{K_{i, 0}}\right)^{2},
$$

where engine speed $\omega_{e}$ is in RPM, engine torque $\tau_{b}$ is in lb.ft, and $K_{i, 0}$ is the input capacity factor for the torque convertor at a speed ratio (output/input) of zero, corresponding to a stalled condition. For an idle speed of 600 RPM, the maximum stall torque for a modern torque convertor is approximately $18.4 \mathrm{lb} \cdot \mathrm{ft}$ (or about $25 \mathrm{~N} \cdot \mathrm{m}$ ). An idle torque slightly lower than this threshold is used as the minimum torque output of the engine; in this case, $20 \mathrm{~N} \cdot \mathrm{m}$ is used. 
This analysis ignores the possibility for the engine to be motored by the wheels in decelerating conditions. This is not seen as problematic, as fuel cutoff can be used during these conditions, meaning that NTELC does not have to be utilized to provide an appropriate amount of air to the cylinders. The engine valves could be left open or closed, or could even alter their timing to provide increased engine compression braking, in such conditions. More detailed treatments of vehicle load analysis and determination of engine speed and torque can be found in [36] for conventional, throttled engines. This analysis takes more real-world factors into consideration, such as the variation of driveline efficiency with operating condition and more detailed behavior of the torque convertor.

\subsection{Required Air Mass Calculation}

Once the engine speed and output torque have been calculated, the required air mass must be calculated, in order to allow calculation of the required valve parameters in the next step. Eq. 5.5) is used in this analysis.

$$
\tau_{b}=\eta_{t h} \frac{n}{4 \pi} e_{c} \frac{m_{a}}{A F}
$$

Here, $\eta_{t h}$ is the thermal efficiency of the engine (defined as the ratio between brake work output and fuel chemical energy input), $n$ is the number of cylinders in the engine, $e_{c}$ is the lower heating value of the fuel, which represents the fuel's chemical energy content, $m_{a}$ is the mass of air that must be present in each of the cylinders, and $A F$ is the air-fuel ratio. It can be noted that $m_{a} / A F$ represents the mass of fuel burned in each cylinder in one engine cycle, $e_{c} m_{a} / A F$ represents the fuel energy present in each cylinder, and $n e_{c} m_{a} / A F$ represents the fuel energy burned by the entire engine over one full engine cycle (two revolutions of the crankshaft for a four-stroke engine).

A brake-specific fuel consumption (BSFC) engine map is used, which gives BSFC (fuel mass per brake energy output) as a function of engine torque and speed. BSFC can be converted to thermal efficiency by Eq. (5.6):

$$
\eta_{t h}=\frac{3.6 \cdot 10^{6}}{e_{c} B S F C}
$$


The factor of 3.6 $10^{6}$ is included to account for units, when $e_{c}$ is in $\mathrm{J} / \mathrm{kg}$ and $B S F C$ is expressed in $\mathrm{g} /(\mathrm{kW} \cdot \mathrm{h})$, as is typical. The brake torque was converted to brake mean effective pressure (BMEP) using Eq. (5.7) (applicable to four-stroke engines), and BMEP was used to look up thermal efficiency at each time step. BMEP was used as a useful quasi-nondimensionalization (because peak BMEP does not vary significantly with engine size for similar types of engines) to help ensure algorithm generality for many specific engines.

$$
B M E P=\frac{4 \pi \tau_{b}}{V_{d}},
$$

where $V_{d}$ is the total engine displacement volume. Fig. 5.4 shows the thermal efficiency map versus engine speed and BMEP.

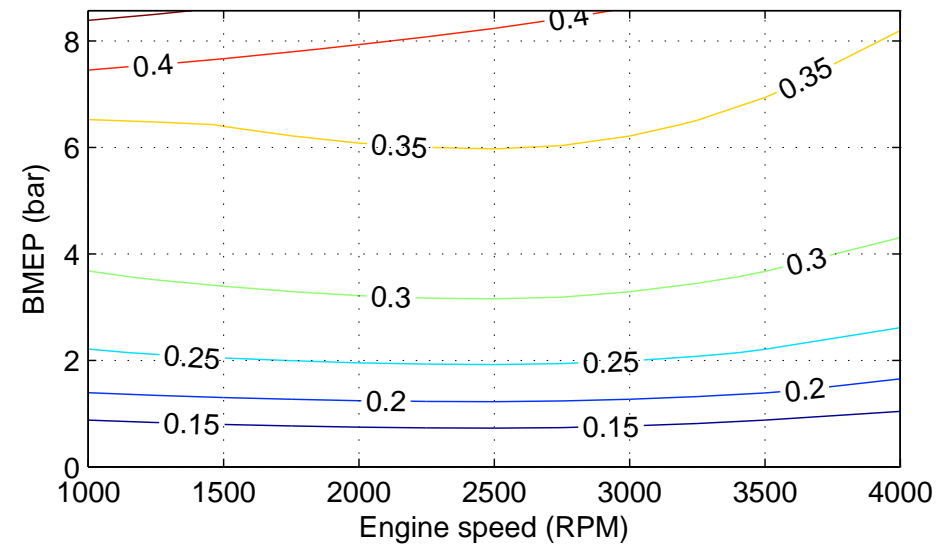

Figure 5.4: Thermal efficiency map used to determine required air mass. Contours represent lines with constant thermal efficiency as labeled

With the thermal efficiency being now determined at each time step, the mass of air required in each cylinder can be solved for. Substituting Eq. (5.5) into Eq. (5.7,

$$
B M E P=\frac{\eta_{t h} n e_{c} m_{a}}{V_{c} A F}
$$

where $V_{c}=V_{d} / n$ is the displacement volume of each cylinder. At this stage, $m_{a}$ was nondimensionalized: normalized air mass $m_{a, n}$ is defined as the ratio of the mass of air in the cylinder to the mass of air at ambient density occupying one cylinder displacement volume. That is, 


$$
m_{a, n}=\frac{m_{a}}{\rho_{a} V_{c}}=\frac{B M E P \cdot A F}{\rho_{a} \eta_{t h} n e_{c}} .
$$

This term is similar in form and meaning to the volumetric efficiency typically associated with throttled SI engines, but differs in that a lower $m_{a, n}$ decreases the brake output of the engine without leading to substantially increased pumping work.

\subsection{Valve Duration and Lift Calculation}

Once the normalized air mass is calculated, the valve parameters to be tracked by the FFVA control system must be determined. There are three primary degrees of freedom to FFVA: valve timing, duration, and maximum lift. To simplify the dimensionality of the problem for current purposes, valve timing was fixed so that intake valve opening (IVO) took place at $15 \mathrm{CAD}$ before top dead center (TDC), which is fairly typical for conventional, cam-driven valvetrains [24, 40].

A further simplification was made to link maximum valve lift to engine speed; lift was set to vary linearly between $3 \mathrm{~mm}$ at idle speed (600 RPM) and $8.2 \mathrm{~mm}$ at the maximum engine speed encountered over the FTP cycle (2500 RPM). This was done with the rationale that little throttling will occur across the intake valve at low engine speeds, even for low valve lifts. Using the lower valve lifts allowed at these speeds will decrease total valvetrain power consumption. As engine speed increases, higher valve lifts are needed to ensure that air flow through the intake valve is still relatively free. A maximum lift of $8.2 \mathrm{~mm}$ was chosen because the equation for $A_{m}$ in [40] (also, see Eq. (5.13) and Fig. 5.7) indicated that the minimum flow area of the valve will not increase any further beyond that lift for the specific valve geometry used in the simulation.

The only remaining valve parameter that must be calculated is thus valve duration. To account for cylinder filling dynamics, a simulation was carried out over the two dimensional [engine speed, valve duration] space. Based on maximum valve lift (determined by engine speed, as discussed above) and valve duration, an approximate valve lift profile as a function of CAD was constructed. Example profiles with 225 CAD duration and different engine speeds (and thus different lifts) are illustrated in Fig. 5.5.

The amounts of time it takes for the valve to reach maximum lift and to return from maximum lift, expressed as a function of lift, were determined by experiments on the system described in Chapter 2. These relationships will depend largely on supply pressure, return spring 


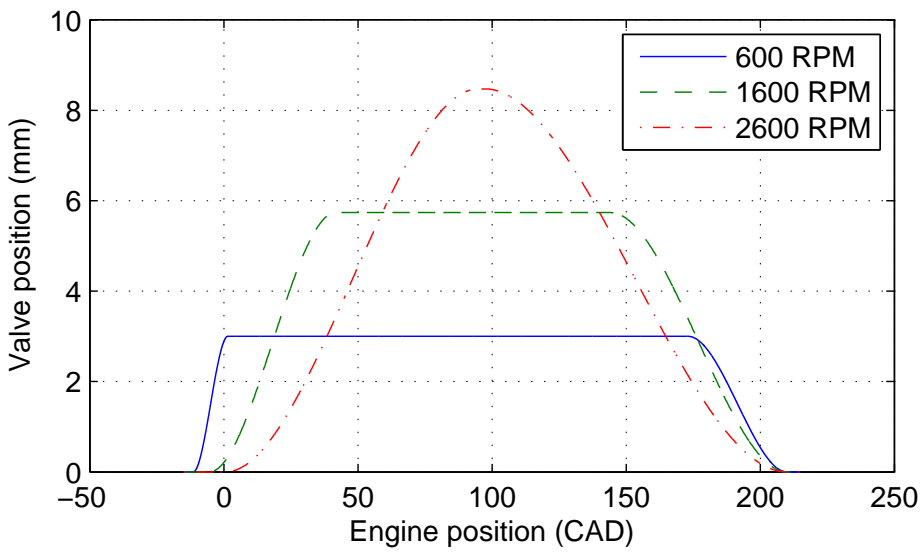

Figure 5.5: Example valve profiles at three different engine speeds

stiffness, and system design. As engine speed increases, each CAD represents a smaller amount of time, and the valve takes a longer amount of time to reach maximum lift (because lift increases with engine speed). There is thus a minimum duration achievable for at each engine speed. In Fig. 5.5, this is shown by the profile at 2600 RPM, where the opening and closing flanks of the valve profile meet in the middle with no dwell at maximum lift separating them.

Next, the induction process was modeled in a discrete-time simulation. Assumptions used were as follows:

1. Fresh charge is considered to be air at ambient conditions $p_{a}, T_{a}$ (see Table 5.1 .

2. Incoming fresh charge mixes thoroughly with the cylinder contends (initially the cylinder volume at IVO of residual at $p_{0}, T_{0}$ [see Table 5.1], representing typical in-cylinder conditions at the end of the exhaust stroke).

3. The valve geometry is according to [40], as discussed below in Eq. (5.13).

4. The discharge coefficient $c_{d}$ is constant throughout the valve's entire lift travel (see Table 5.1.

5. Incoming fresh charge and residual are pure air, an ideal gas with temperature-dependent specific heat ratio as given in [41]. 
6. Inertial effects are ignored.

7. Pressure equilibrium is maintained within the cylinder.

8. No chemical reactions take place during the intake process.

9. Piston motion is described by crank-slider geometry with dimensions as discussed earlier.

10. Engine speed is assumed to be constant over the entire intake stroke.

11. Temperature in the cylinder at each time step is determined by the mass-weighted average of the current temperature of the cylinder contents and the temperature of the air entering the cylinder during the current time step. During backflow conditions, the temperature in the cylinder remains constant.

In the simulation, the mass flow through the valve was modeled using Eqs. 5.10:

$$
\begin{gathered}
\dot{m}_{a}=c_{d} A_{m} \frac{p_{u}}{\sqrt{R_{a} T_{u}}} \Psi\left(\frac{p_{u}}{p_{d}}, \gamma_{u}\right) \\
\Psi\left(\frac{p_{u}}{p_{d}}, \gamma_{u}\right)= \begin{cases}\sqrt{\gamma_{u}\left(\frac{2}{\gamma_{u}+1}\right)^{\frac{\gamma_{u}+1}{\gamma_{u}-1}}} & \text { for } \frac{p_{u}}{p_{d}} \geq\left(\frac{\gamma_{u}+1}{2}\right)^{\frac{\gamma_{u}}{\gamma_{u}-1}} \\
\left(\frac{p_{u}}{p_{d}}\right)^{\frac{1}{\gamma_{u}}} \sqrt{\frac{2 \gamma_{u}}{\gamma_{u}-1}\left[\left(\frac{p_{u}}{p_{d}}\right)^{\frac{\gamma_{u}-1}{\gamma_{u}}}-1\right]} & \text { for } \frac{p_{u}}{p_{d}}<\left(\frac{\gamma_{u}+1}{2}\right)^{\frac{\gamma_{u}}{\gamma_{u}-1}},\end{cases}
\end{gathered}
$$

where $\dot{m}_{a}$ is the mass flow rate through the valve at a particular instant, $c_{d}$ is the discharge coefficient, $A_{m}$ is the minimum flow area through the valve, $p$ denotes pressure, $R_{a}$ is the specific gas constant for air, $T$ denotes absolute temperature, $\gamma$ is the specific heat ratio of the gas, and subscripts $u$ and $d$ refer to upstream and downstream conditions, respectively.

The simulation was set up to allow flow in both directions through the valve depending on whether the in-cylinder pressure was higher than that outside the intake valve. The temperature of the charge in the cylinder was calculated as described in assumption 11 above. The pressure in the cylinder was then calculated using the ideal gas law and the mass in the cylinder, the temperature of the cylinder, and the volume of the cylinder. The cylinder volume $v_{c y l}$ was calculated at each time step based on cylinder, crank, and connecting-rod geometry from Eq. (5.11):

$$
v_{c y l}=\left(\frac{1}{2}+r_{c s}-\cos \left(\theta_{e}\right) / 2-\sqrt{r_{c s}^{2}-\frac{\sin ^{2}\left(\theta_{e}\right)}{4}}\right) \frac{\pi s b^{2}}{4}+v_{c}
$$


where $r_{c s}$ is the connecting-rod-to-stroke ratio, $\theta_{e}$ is the current engine crank position, $s$ is the engine stroke, $b$ is the engine bore, and $v_{c}$ is the clearance volume of the cylinder (i.e., cylinder volume at TDC), determined by Eq. (5.12):

$$
v_{c}=\frac{V_{c}}{r-1}
$$

where $r$ is the compression ratio of the engine. The minimum flow area through the valve $A_{m}$ was calculated using the calculated valve lift trajectory and typical valve geometry and area formula as set forth Eq. [5.13] [40] at each time step:

$$
A_{m}= \begin{cases}0 & \text { for } l_{\text {act }} \leq 0 \\ \pi n_{v} l_{a c t} \cos \beta\left(d_{v}-2 w+\frac{l_{a c t}}{2} \sin 2 \beta\right) & \text { for } 0<l_{a c t} \leq \frac{w}{\sin \beta \cos \beta} \\ \pi n_{v}\left(d_{v}-w\right) \sqrt{\left(l_{a c t}-w \tan \beta\right)^{2}+w^{2}} & \text { for } \frac{w}{\sin \beta \cos \beta}<l_{a c t} \leq w \tan \beta \\ & \quad+\sqrt{\left(\frac{d^{2}-d_{s}^{2}}{4\left(d_{v}-w\right)}\right)^{2}-w^{2}} \\ & \text { for } w \tan \beta+\sqrt{\left(\frac{d^{2}-d_{s}^{2}}{4\left(d_{v}-w\right)}\right)^{2}-w^{2}}<l_{a c t}\end{cases}
$$

where $l_{\text {act }}$ is the desired valve lift at the current time step, $n_{v}$ is the number of identical intake valves per cylinder, $d_{v}$ is the valve head diameter (equal to the outer seat diameter), $\beta$ is the seat angle, $d$ is the inner seat diameter (equal to the inner port diameter), $w$ is the seat width (equal to $\frac{1}{2}\left(d_{v}-d\right)$ ), and $d_{s}$ is the valve stem diameter. The geometrical meanings of each of these are illustrated in Fig. 5.6, and typical values as described in were used for all of these parameters, as described in [40] and given in Table 5.1] See Fig. 5.7 for a plot of total minimum flow area (that is, including both intake valves) versus valve lift for the parameters used in the simulation. 


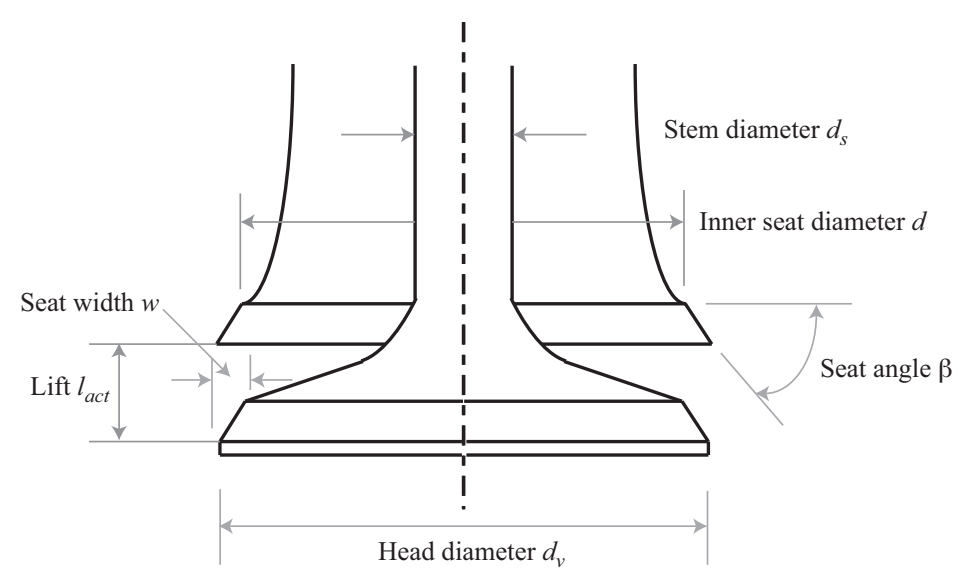

Figure 5.6: Valve geometry schematic, adopted from [40]

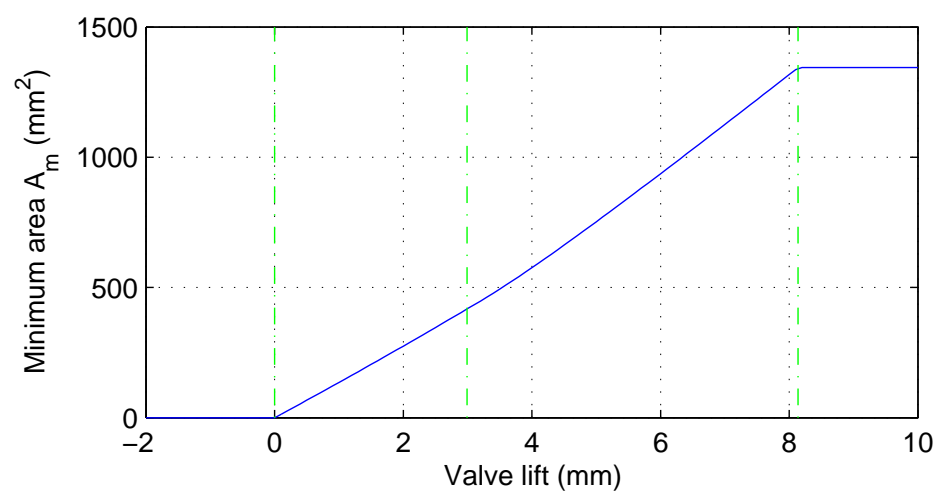

Figure 5.7: Minimum valve flow area as a function of valve lift. Vertical lines indicate transitions between flow regimes as listed in Eq. 5.13

This simulation gave the normalized air mass for the full range of engine speeds and valve durations, which was then recorded in a look-up table. These results are presented in Fig. 5.8 with the symbol on each trace denoting the earliest possible IVC under the FFVA system assumptions used. Note that, at high engine speeds, low $m_{a, n}$ are not achievable by EIVC due to the actuation constraints of the valve. Two different strategies were therefore used in the main NTELC via FFVA simulation to calculate valve duration. The first utilized a hybrid EIVC/LIVC strategy, in which the intake valve would close early if the desired $m_{a, n}$ was achievable by 
EIVC, and would close late otherwise. The second strategy was pure LIVC, in which the valve would always close after the peak $m_{a, n}$ point to achieve NTELC.

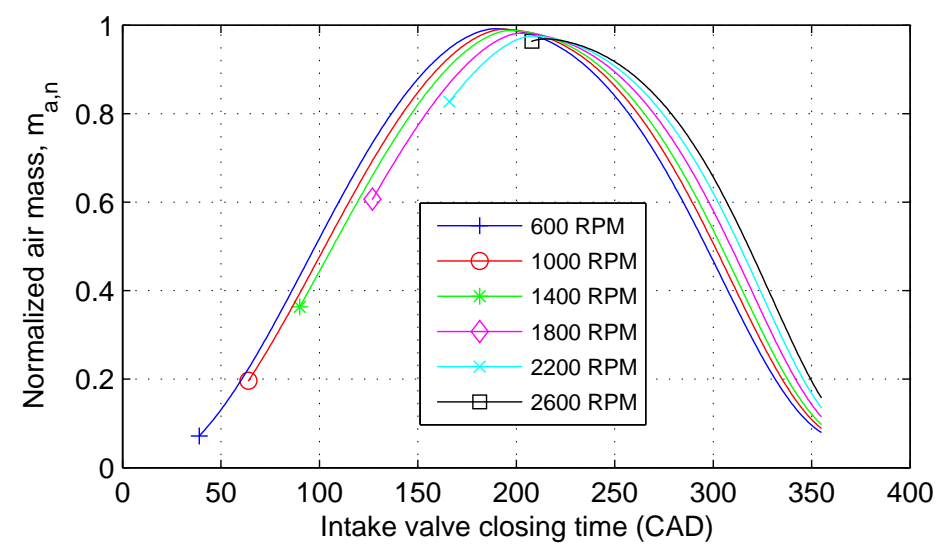

Figure 5.8: Plot of normalized air mass versus IVC timing at different engine speeds

Another treatment of the determination of valve parameters from required air mass is given in [33], where it is assumed that any commanded valve parameters can be tracked perfectly. There, the controller was designed to adaptively modify these valve parameters to account for modeling uncertainties, change in engine parameters with wear, etc. In the current work, the focus is on the design of a lower-level controller to ensure that the FFVA system tracks the desired valve event parameters obtained from the previous analysis. 


\section{Chapter 6}

\section{Simulation and Experimental Results}

\subsection{FTP Cycle Results}

As per the vehicle load analysis presented in Chapter 5 the tractive effort required at the wheels to follow the FTP driving cycle is shown in Fig. 6.1 The engine brake torque output, engine speed, and transmission gear were determined as described in Chapter 5 They are plotted in Figs. 6.2, 6.3 and 6.4, respectively. The required normalized air mass was calculated at each time step and is plotted in Fig. 6.5

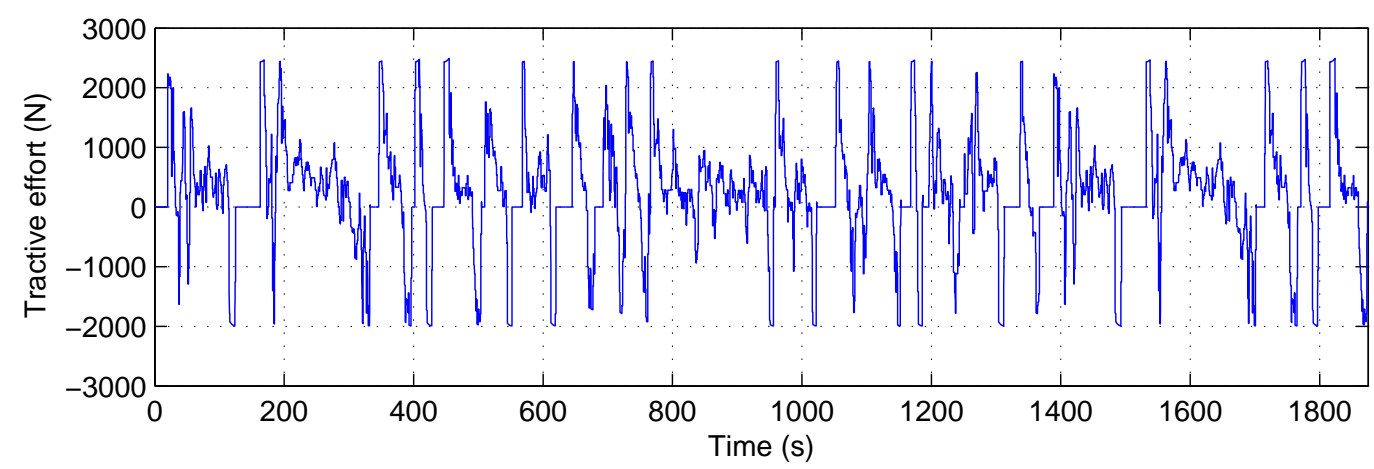

Figure 6.1: Calculated tractive effort required to follow the FTP cycle 


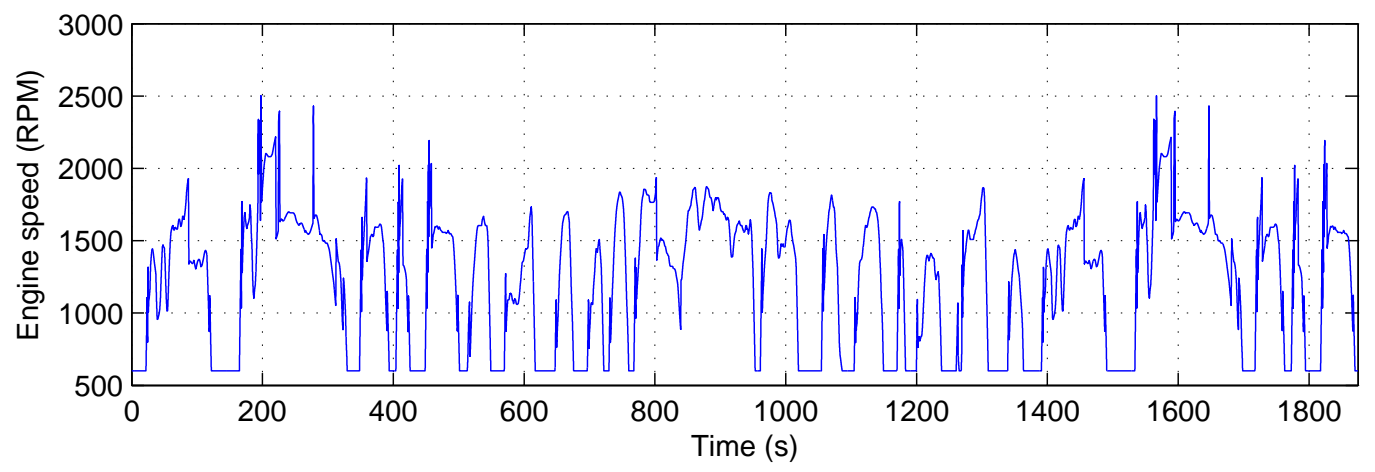

Figure 6.2: Engine speed over the FTP cycle

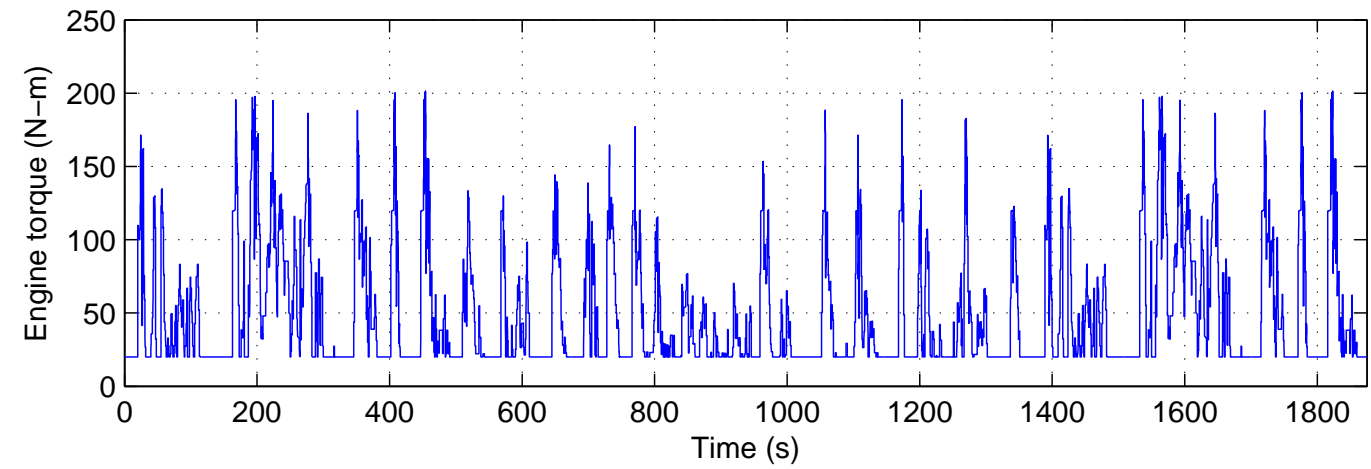

Figure 6.3: Engine brake torque output over the FTP cycle 


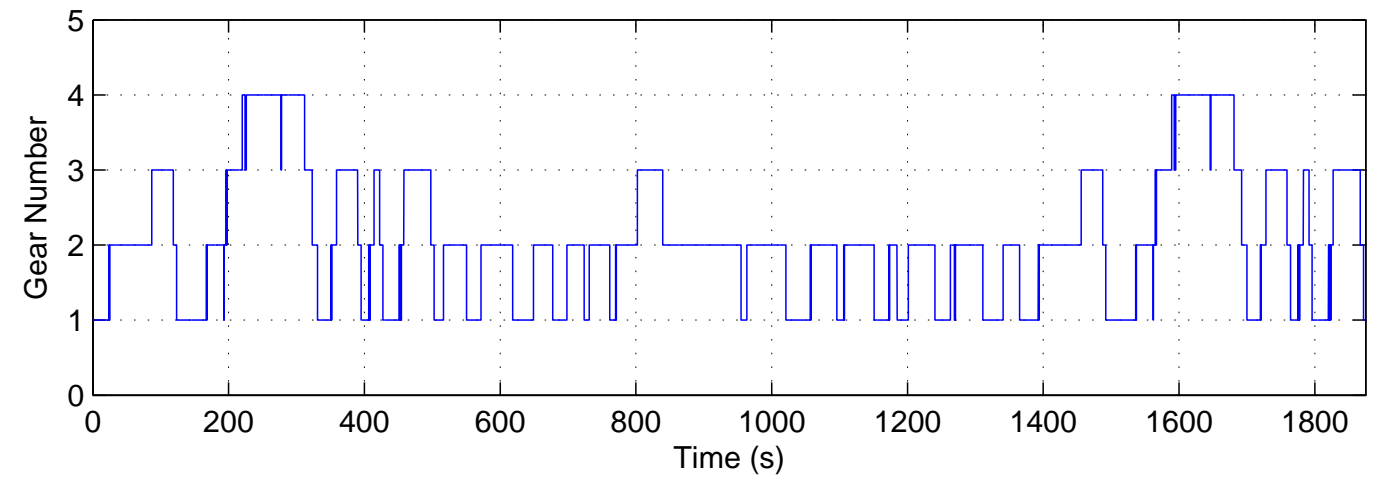

Figure 6.4: Transmission gear number over the FTP cycle

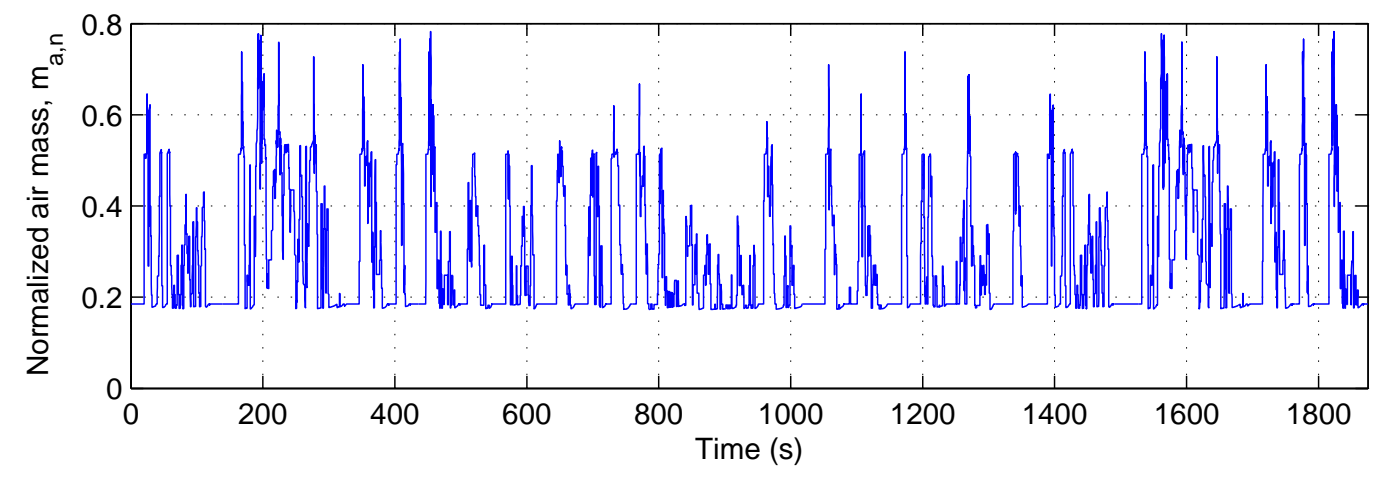

Figure 6.5: Required normalized air mass to follow the FTP cycle 


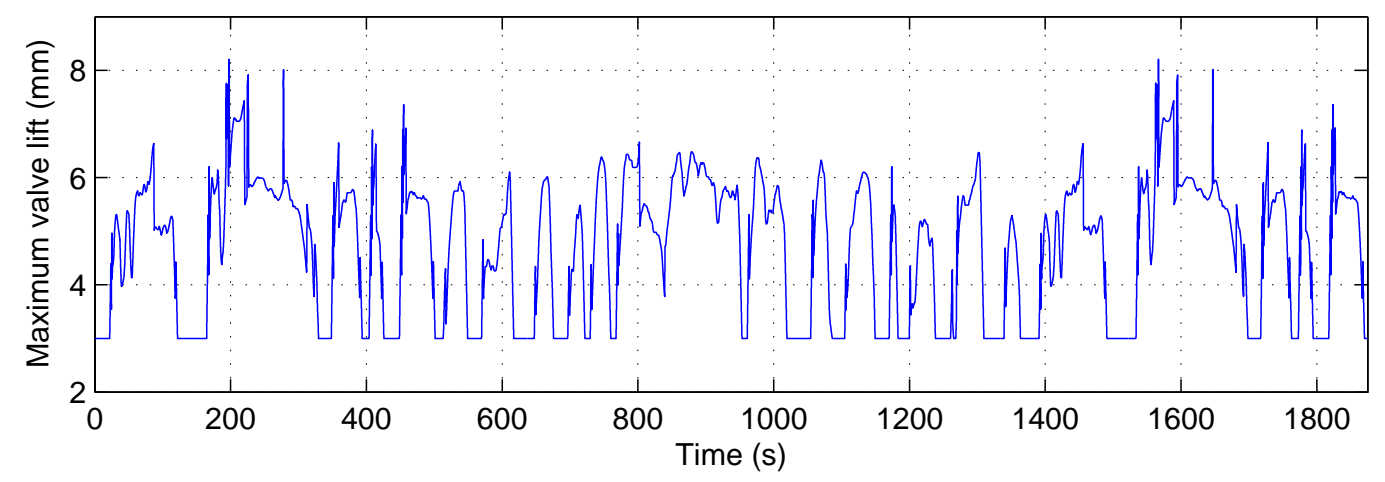

Figure 6.6: Maximum valve lift trace over the FTP cycle

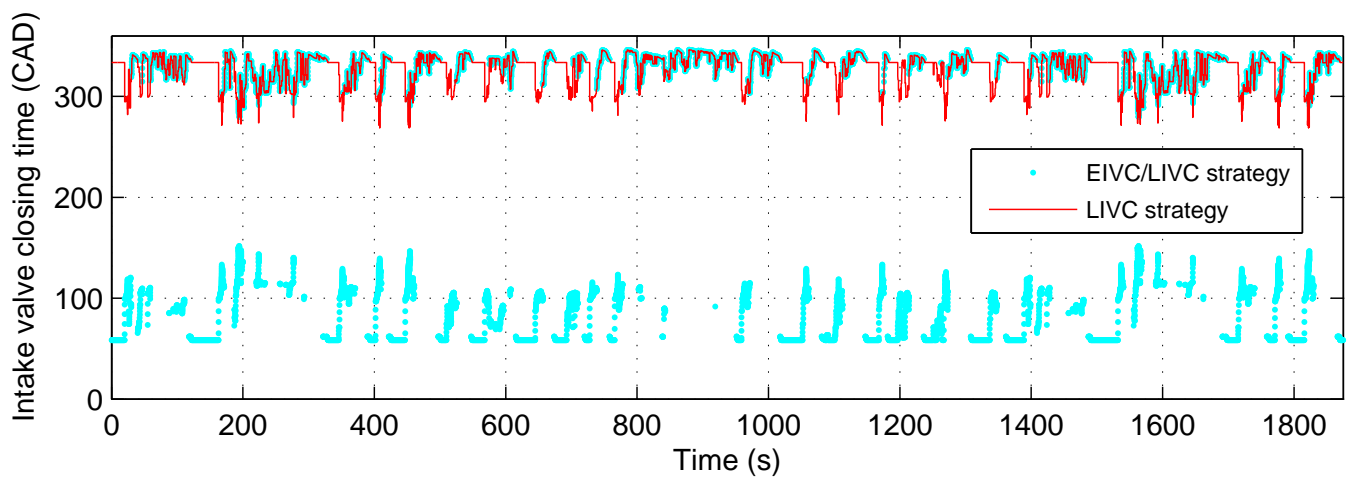

Figure 6.7: Intake valve closing time traces over the FTP cycle for EIVC/LIVC and LIVC strategies

Note that the FTP cycle is a fairly conservative driving cycle, in that it does not approach the full air-handling capabilities of the engine; Fig. 5.8 demonstrates that at engine speeds in the range seen here, $m_{a, n}$ can go up to 0.95 and above, while the maximum $m_{a, n}$ required over the FTP cycle is approximately 0.758 , as shown in Fig. 6.5. It is also conservative in that the engine speed remains fairly low; an engine such as this could be expected to achieve maximum speeds of 6000 RPM or higher, while Fig. 6.2 shows that the maximum engine speed over the FTP cycle is around 2500 RPM. Also note that the minimum normalized air mass, is slightly below 20\%. This agrees well with the figure given in [29]. 
Finally, the maximum valve lift and IVC times were calculated and are given in Figs. 6.6 and 6.7 respectively. Recall that the IVO time was fixed at 15 CAD before TDC, fixing the timing of the valve event and also allowing a straightforward calculation of the valve duration from IVC and IVO. Also note the two NTELC strategies shown in Fig. 6.7

\subsection{Valve Tracking Results}

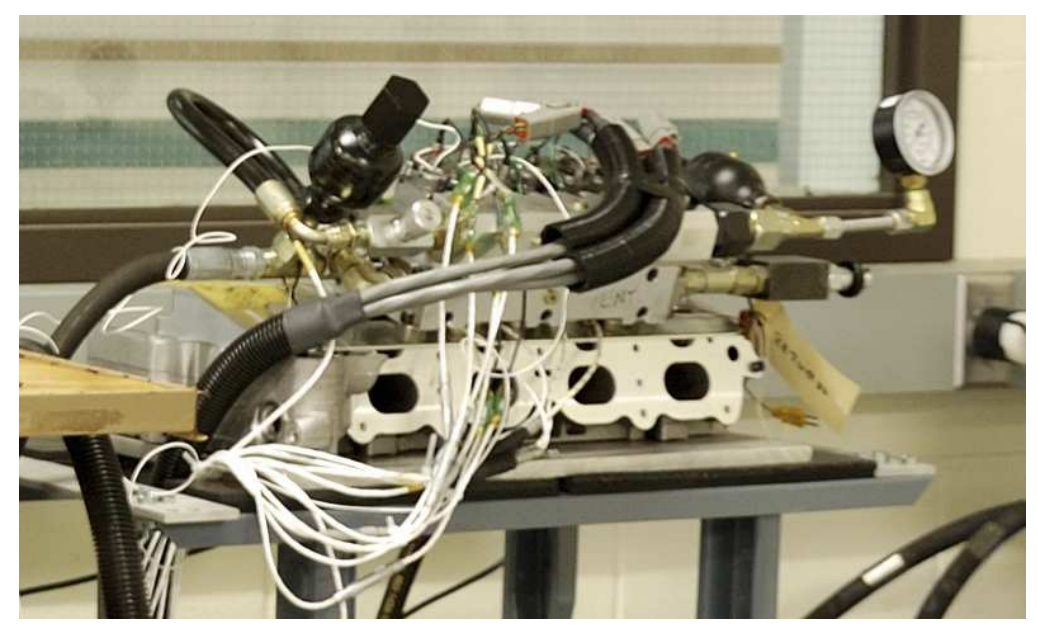

Figure 6.8: Prototype experimental setup

A compact multi-cylinder FFVA setup, shown in Fig. 6.8 was used to test the developed control algorithm over the FTP cycle traces developed in Chapter 5. The controller was implemented on one of its valves; little interaction was observed between valves of adjacent cylinders actuated 180 or $360 \mathrm{CAD}$ out of phase over the range of engine speeds used in testing.

Figs. 6.9 and 6.10 show the lift and duration tracking errors over the FTP cycle, respectively. See Figs. 6.6 and 6.7 for the desired lift and IVC traces, respectively; the tracking error presented is for the EIVC/LIVC case. Note that tracking of even very large (>100 CAD) duration transients (see Fig. 6.7 produces no noticeable disturbance in the tracking error in Fig. 6.10,

In actual practice, the seating velocity bound is not fixed independently of lift. To illustrate this, the seating velocity bound was set as a function of desired lift. Furthermore, the higher 


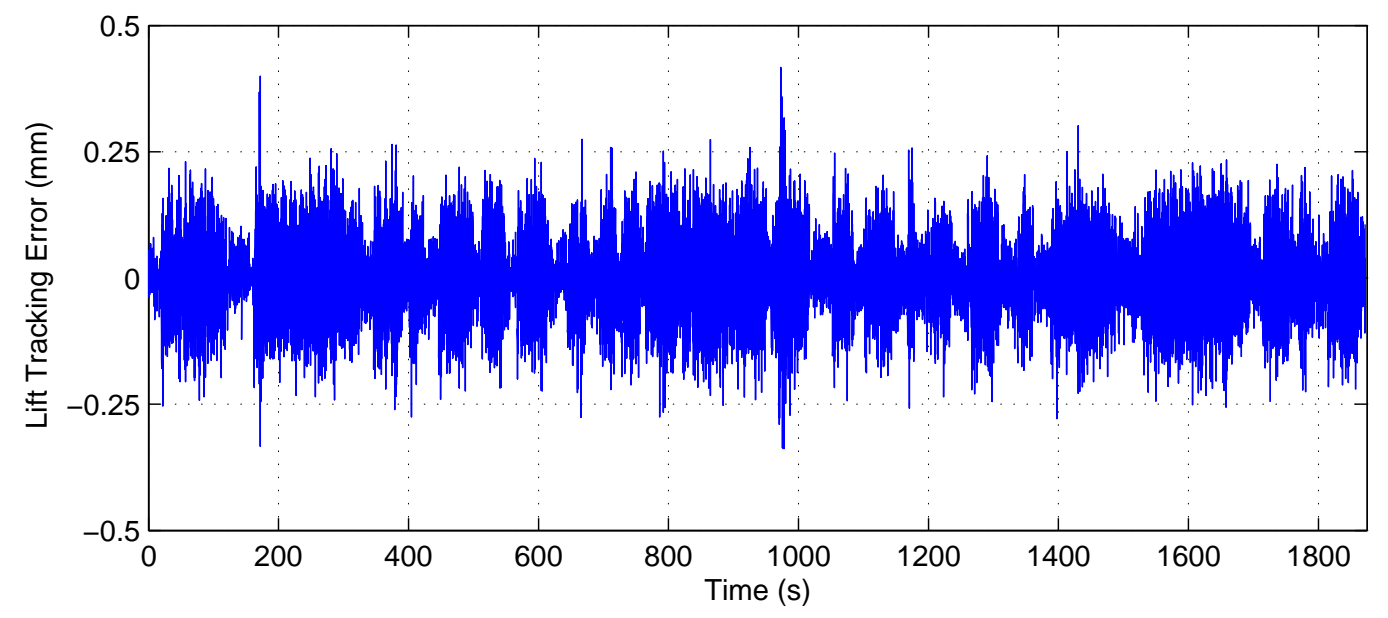

Figure 6.9: Lift tracking error for controller over FTP cycle

variability at low seating velocities would be mitigated; recall from Chapter 5 that lift was set as a function of engine speed. This means that the low-lift, low-seating-velocity case occurs only at low engine speeds, at which each CAD represents a longer amount of time. The seating velocity and seating velocity bound for this case over the FTP cycle are shown in Fig.6.11 Note that the seating velocity bound is effectively obeyed. The controller tunes itself to minimize the closing time variability by increasing seating velocity as far as possible while maintaining the seating velocity threshold.

Fig. 6.12 shows a histogram and cumulative probability function for lift tracking error. Fig. 6.13 shows a histogram and cumulative probability function for duration tracking error. Fig. 6.14 shows a histogram and cumulative probability function for seating velocity violations. Note that this figure displays only seating velocity violations (i.e, when the desired seating velocity is higher in magnitude than the bound), as any seating velocity below the desired bound is considered acceptable. Table 6.2 shows key statistics for each of these tracking errors over the 19145 valve events of the FTP cycle simulation; it can be seen that tracking performance is very good despite the highly transient nature of the desired traces. This table, along with Figs. 6.12 and 6.13 show that $99 \%$ of all cycles have lift and seating time errors of less than $0.185 \mathrm{~mm}$ and $4.90 \mathrm{CAD}$, respectively. It also can be seen in Fig. 6.14 that seating velocity violations occur $11.99 \%$ of the time, and Table 6.2 shows that even when seating violations 


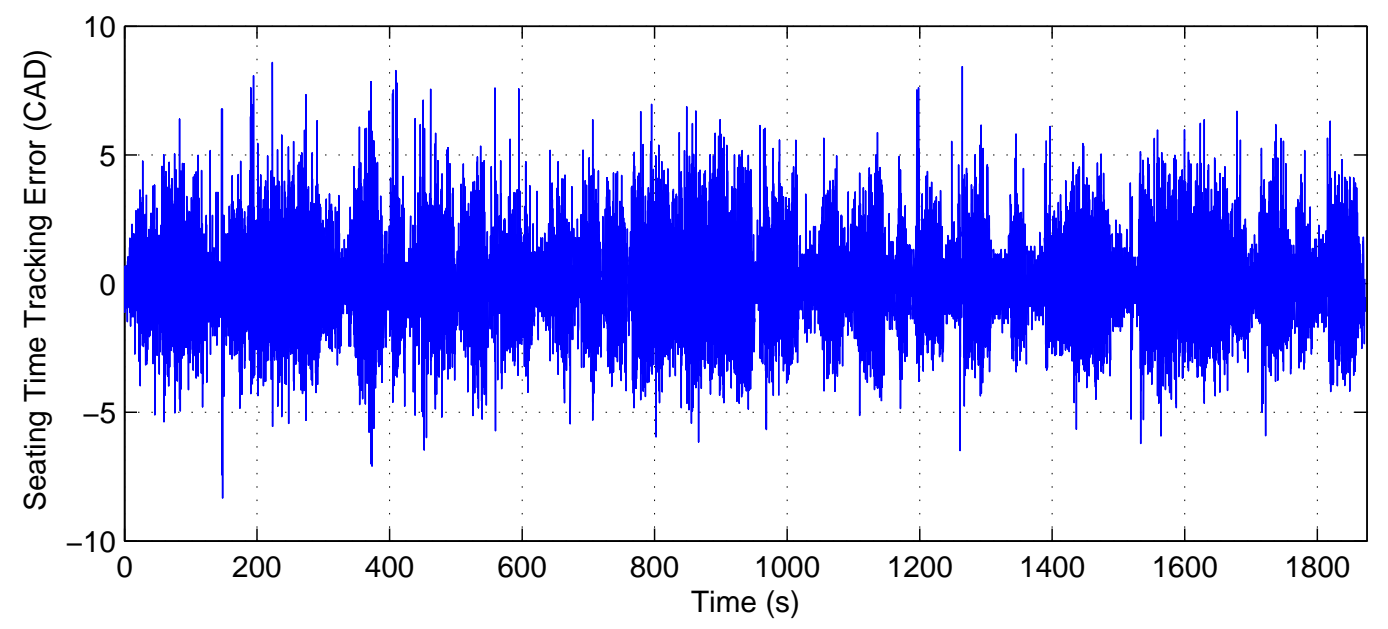

Figure 6.10: IVC tracking error for controller over FTP cycle

occur, they are relatively small in magnitude ( $99 \%$ of all cycles have seating velocities less than $0.0328 \mathrm{~m} / \mathrm{s}$ over the bound). Because the number of valve cycles over which these statistics are calculated is so large, we have good confidence that these statistics represent a true picture of the system's performance.

Table 6.1: Key statistics from tracking of FTP cycle data

\begin{tabular}{llll}
\hline \hline Metric & Valve lift error & Seating time error & Seating velocity violations \\
\hline Median & $\pm 5.00 \cdot 10^{-5} \mathrm{~m}$ & $\pm 1.10 \mathrm{CAD}$ & Within bound \\
$90 \%$ ile & $\pm 1.26 \cdot 10^{-4} \mathrm{~m}$ & $\pm 2.79 \mathrm{CAD}$ & $<0.0042 \mathrm{~m} / \mathrm{s}$ over bound \\
$95 \%$ ile & $\pm 1.52 \cdot 10^{-4} \mathrm{~m}$ & $\pm 3.47 \mathrm{CAD}$ & $<0.0175 \mathrm{~m} / \mathrm{s}$ over bound \\
$99 \%$ ile & $\pm 2.03 \cdot 10^{-4} \mathrm{~m}$ & $\pm 4.87 \mathrm{CAD}$ & $<0.0429 \mathrm{~m} / \mathrm{s}$ over bound \\
\hline \hline
\end{tabular}




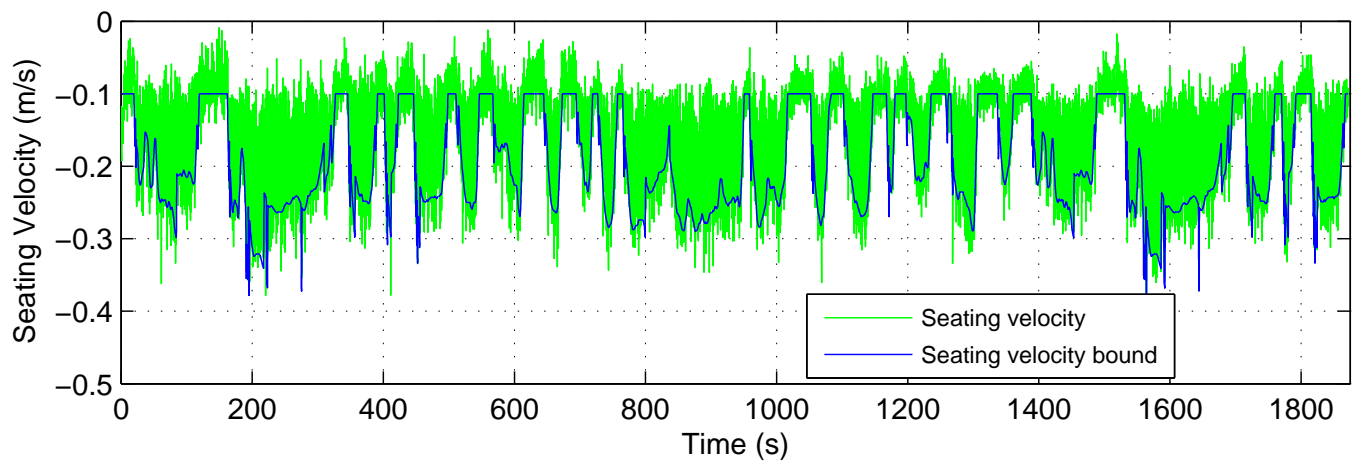

Figure 6.11: Seating velocity and desired seating velocity bound over FTP cycle

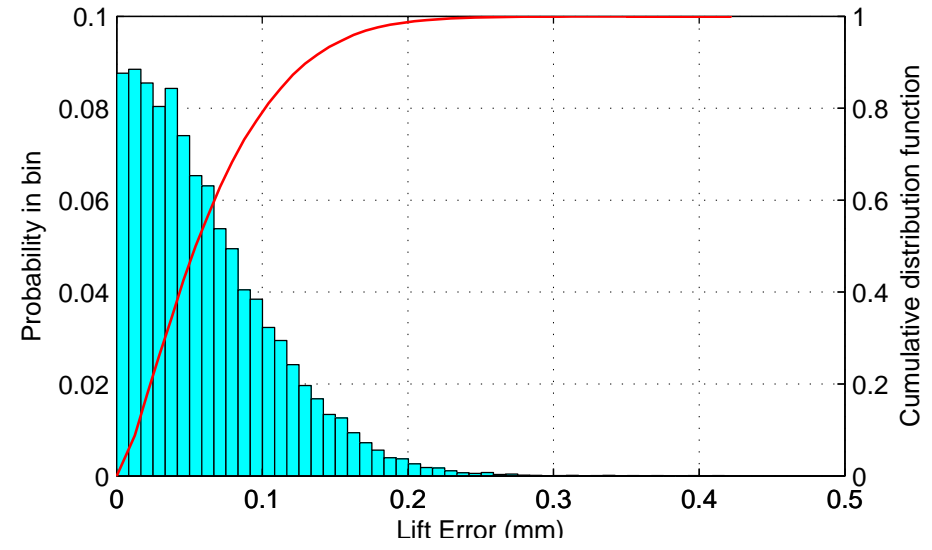

Figure 6.12: Histogram (left y-axis) and cumulative distribution (right y-axis) for lift tracking error magnitude over FTP cycle 


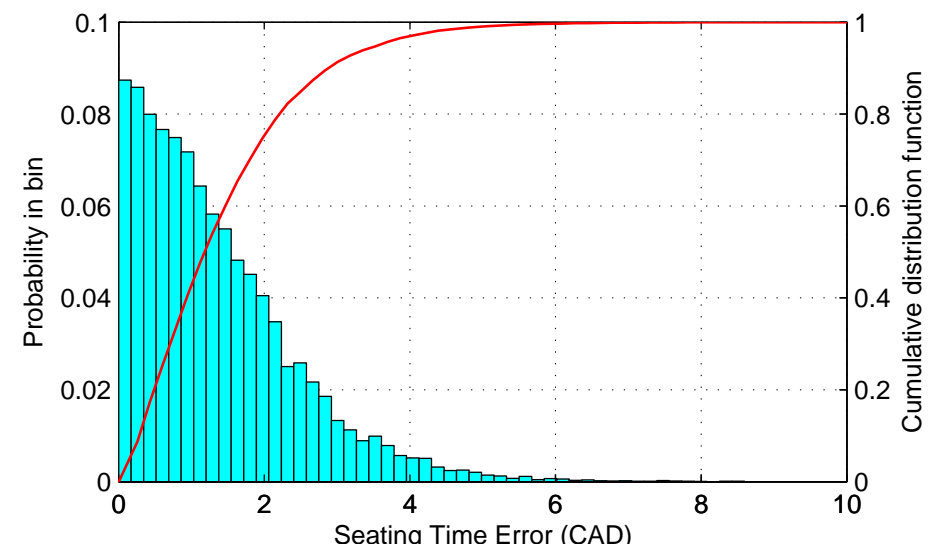

Figure 6.13: Histogram (left y-axis) and cumulative distribution (right y-axis) for duration tracking error magnitude over FTP cycle

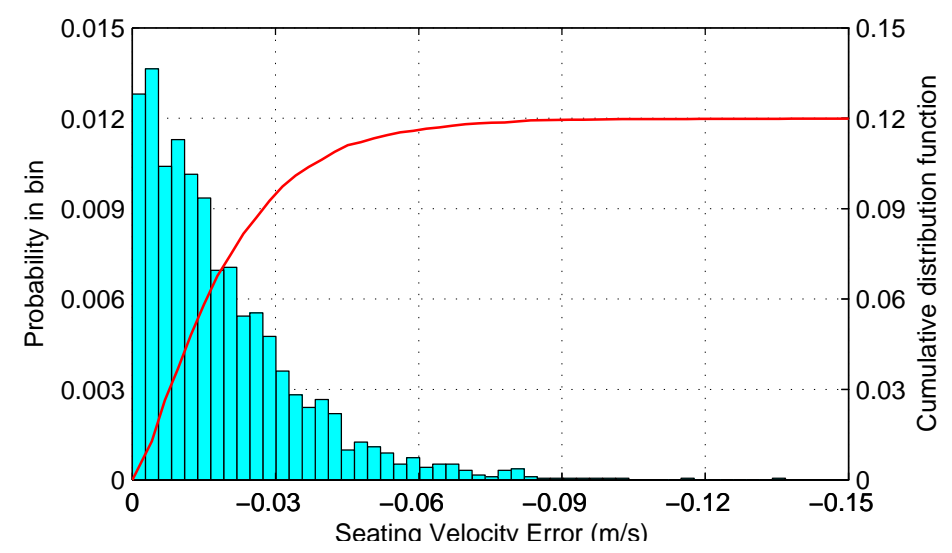

Figure 6.14: Histogram (left y-axis) and cumulative distribution (right y-axis) for seating velocity violations over FTP cycle. Note that cumulative probability of violations is calculated with respect to total number of cycles 


\section{Chapter 7}

\section{Discussion and Conclusion}

This thesis presents the application of iterative learning control for a new camless engine valve actuation system with an internal feedback mechanism. The internal feedback system has the benefit of simplifying the external controls. The proposed learning controller combines feedback and feed-forward components to reliably track transients in desired lift and closing time with minimal violations of a maximum seating velocity constraint. The precise tracking performance allows cycle-to-cycle control of the profile characteristics (timing, lift, and duration) of individual engine valves, which in turn has benefits in engine power, efficiency, and advanced combustion control.

The iterative learning control is then implemented on a prototype camless system for nonthrottled engine load control. The procedure for calculating the intake valve parameters (lift and duration) based on vehicle load analysis of a driving cycle is described. Detailed experimental data corresponding to the tracking of these valve parameters are presented. Excellent tracking over the Federal Test Procedure driving cycle is achieved; 99\% of the time, the lift error is $0.203 \mathrm{~mm}$ or less, the duration error is 4.87 CAD or less, and the seating velocity is $0.0429 \mathrm{~m} / \mathrm{s}$ or less over the desired bound. Seating velocity violations occur only $11.99 \%$ of the time. These statistics are calculted over all 19145 valve events of the driving cycle. This level of tracking performance and with the comparatively low calibration effort required to achieve it suggest that a controller similar to this shows promise in being feasibly implementable in a production context in the relatively near-term.

Future work includes investigating additional degrees of flexibility such as intake valve 
opening timing as well as exhaust valve timing and duration. However, these additional flexibilities correspond to a higher input dimensionality and thus require more calibration effort. This further highlights the importance of a systematic control method to ensure precise valve tracking performance. Finally, testing of the FFVA system and control system on a firing engine would help further validate the NTELC analysis and ILC presented herein. 


\section{References}

[1] T. Hosaka and M. Hamazaki, "Development of the variable valve timing and lift (VTEC) engine for the Honda NSX," SAE Tech. Paper Series, No. 910008, 1991.

[2] C. Brüstle and D. Schwarzenthal, "VarioCam Plus - A Highlight of the Porsche 911 Turbo Engine," SAE Technical Paper Series, No. 2001-01-0245, 2001.

[3] R. Flierl and M. Klüting, "The Third Generation of Valvetrains - New Variable Valvetrains for Throttle-Free Load Control," SAE Technical Paper Series, No. 2000-01-1227, 2000.

[4] V. Picron, Y. Postel, E. Nicot, and D. Durrieu, "Electro-Magnetic Valve Actuation System: First Steps toward Mass Production," SAE Technical Paper Series, No. 2008-01-1360, 2008.

[5] J.W.G. Turner, M.D. Bassett, R.J. Pearson G. Pitcher, and K.J. Douglas, "New Operating Strategies Afforded by Fully Variable Valve Trains," SAE Technical Paper Series, No. 2004-01-1386, 2004.

[6] M.M. Schecter and M.B. Levin, "Camless Engine," SAE Technical Paper Series, No. 960581, 1996.

[7] M. Fujiwara, K. Kumagai, M. Segawa, R. Sato, and Y. Tamura, "Development of a 6Cylinder Gasoline Engine with New Variable Cylinder Management Technology," SAE Technical Paper Series, No. 2008-01-0610, 2008.

[8] N. Milovanovic, R. Chen, and J. Turner, "Influence of the Variable Valve Timing Strategy on the Control of a Homogeneous Charge Compression (HCCI) Engine," SAE Technical Paper Series, No. 2004-01-1899, 2004. 
[9] P.A. Caton, H.H. Song, N.B. Kaahaaina, and C.F. Edwards, "Strategies for Achieving Residual-Effected Homogeneous Charge Compression Ignition Using Variable Valve Actuation,” SAE Technical Paper Series, No. 2005-01-0165, 2005.

[10] W. Hoffmann, K. Peterson, and A.G. Stefanopoulou, "Iterative Learning Control for Soft Landing of Electromechanical Valve Actuator in Camless Engines," IEEE Transactions on Control System Technology, Vol. 11, No. 2, 2003.

[11] Z. Sun and T.W. Kuo, "Transient Control of Electro-Hydraulic Fully Flexible Engine Valve Actuation System," IEEE Transactions on Control System Technology, Vol. 18, No. 3, 2010.

[12] Z. Sun, "Electrohydraulic Fully Flexible Valve Actuation System With Internal Feedback," ASME Journal of Dynamic Systems, Measurement, and Control, Vol. 131, 2009.

[13] Z. Sun, "Engine valve actuator assembly with dual automatic regulation," U.S. Patent 6959673 B2, 2005.

[14] P. Gillella and Z. Sun, "Design, Modeling, and Control of a Camless Valve Actuation System With Internal Feedback," IEEE/ASME Transactions on Mechatronics, DOI 10.1109/TMECH.2010.2045656, 2010.

[15] S. Arimoto, S. Kawamura, and F. Miyazaki, "Bettering Operation of Robots by Learning," Journal of Robotic Systems, Vol. 2, No. 1, 1984.

[16] H.S. Ahn, K.L. Moore, and Y.Q. Chen, Iterative Learning Control: Robustness and Monotonic Convergence for Interval Systems, Springer, 2007.

[17] K.L. Moore, Iterative Learning Control for Deterministic Systems, Springer-Verlag, 1993.

[18] Y.Q. Chen and C. Wen, Iterative Learning Control: Convergence, Robustness, and Applications, Springer, 1999.

[19] D.A. Bristow, M. Tharayil, and A.G. Alleyne, "A Survey of Iterative Learning Control: A Learning-Based Method for High-Performance Tracking Control," IEEE Control Systems Magazine, June 2006. 
[20] M. Norrlöf and S. Gunnarsson, "Time and frequency domain convergence properties in iterative learning control," International Journal of Control, Vol. 75, No. 14, 2002.

[21] G. Oriolo, S. Panzieri, and G. Ulivi, "Cyclic Learning Control of Chained-Form Systems with Application to Car-Like Robots," Proceedings of $13^{\text {th }}$ Triennial World Congress of IFAC, 1996.

[22] K.L. Moore, M. Dahleh, and S.P. Bhattacharyya, "Iterative Learning Control: A Survey and New Results," Journal of Robotic Systems, Vol. 5, No. 9, 1992.

[23] K.L. Moore and J.X. Xu, Editiorial: Special issue on iterative learning control, International Journal of Control, Vol. 73, No. 10, 2000.

[24] R. Stone, Introduction to Internal Combustion Engines, $3^{\text {rd }}$ Edition, Warrendale, PA.: Society of Automotive Engineers, 1999.

[25] A.A. Boretti and H.C. Watson, "The lean burn direct injection jet ignition gas engine," International Journal of Hydrogen Energy Vol. 34, 2009.

[26] N. Ueda, H. Sakai, N. Iso, and J. Sasaki, "A Naturally Aspirated Miller Cycle Gasoline Engine - Its Capability of Emission, Power and Fuel Economy," SAE Technical Paper Series, No. 960589, 1996.

[27] O. Vogel, K. Roussopoulos, L. Guzzella, and J. Czekaj, "An Initial Study of Variable Valve Timing Implemented with a Secondary Valve in the Intake Runner," SAE Technical Paper Series, No. 960590, 1996.

[28] J.H. Tuttle, "Controlling Engine Load by Means of Late Intake-Valve Closing," SAE Technical Paper Series, No. 800794, 1980.

[29] J.H. Tuttle, "Controlling Engine Load by Means of Early Intake-Valve Closing," $S A E$ Technical Paper Series, No. 880408, 1982.

[30] R. Flierl, S. Schmitt, and W. Hannibal, "First Results of a 1-Cylinder Engine with Variable Compression Ratio, Fully Mechanically Variable Inlet and Exhaust Valve Actuation," SAE Technical Paper Series, No. 2009-01-1836, 2009. 
[31] A. Boretti, "Use of Variable Valve Actuation to Control the Load In a Direct Injection, Turbocharged, Spark-Ignition Engine,” SAE Technical Paper Series, No. 2010-01-2225, 2010.

[32] J. Ma, G.G. Zhu, and H. Schock, "Adaptive Control of a Pneumatic Valve Actuator for an Internal Combustion Engine," IEEE Transactions on Control Systems Technology, DOI 10.1109/TCST.2010.2054091, 2010.

[33] M.S. Ashhab, A.G. Stephanopoulou, J.A. Cook, and M.B. Levin, "Camless Engine Control for Robust Unthrottled Operation,” SAE Technical Paper Series, No. 981031, 1998.

[34] "Testing \& Measuring Emissions: Dynamometer Driver's Aid," United States Environmental Protection Agency, $<$ http://www.epa.gov/nvfel/testing/dynamometer.htm $>$, last updated 6-16-2010, retrieved 12-12-2010.

[35] C.E. Burke, L.H. Nagler, E.C. Campbell, L.C. Lundstron, W.E. Zierer, H.L. Welch, T.D. Kosier, and W.A. Mcconnell, "Where Does All the Power Go?", Symposium, SAE Transactions, Vol. 65, No. 570058, 1957.

[36] P.N. Blumberg, "Powertrain Simulation: A Tool for the Design and Evaluation of Engine Control Strategies in Vehicles," SAE Technical Paper Series, No. 760158, 1976.

[37] R.A. Bechtold, "Ingredients of Fuel Economy," SAE Technical Paper Series, No. 790928, 1979.

[38] M.A. Kluger and D.M. Long, "An Overview of Current Automatic, Manual, and Continuously Variable Transmission Efficiencies and Their Projected Future Improvements," SAE Technical Paper Series, No. 1999-01-1259, 1999.

[39] M.A. Kluger and J.J. Greenbaum, "Automatic Transmission Efficiency Characteristics and Gearbox Torque Loss Regression Techniques," SAE Technical Paper Series, No. 930907, 1993.

[40] J.B. Heywood, Internal Combustion Engine Fundamentals, New York: McGraw-Hill, 1988. 
[41] I. Urieli, "Specific Heat Capacities of Air," Ohio University, <http: / /www . ohio. edu/mechanical/thermo/property_tables/air/air_Cp_Cv.html>, last updated 7-26-2008, retrieved 12-10-2010. 


\section{Appendix A}

\section{Acronyms}

Care has been taken in this thesis to minimize the use of acronyms, but this cannot always be achieved. This appendix contains a table of acronyms and their meaning.

Table A.1: Acronyms

\begin{tabular}{|l|l|}
\hline Acronym & Meaning \\
\hline \hline BDC & Bottom Dead Center \\
BMEP & Brake Mean Effective Pressure \\
BSFC & Brake-Specific Fuel Consumption \\
CAD & Crank-Angle Degree \\
EIVC & Early Intake Valve Closing \\
FFVA & Fully-Flexible Valve Actuation \\
FTP & Federal Test Procedure \\
HCCI & Homogeneous-Charge Compression Ignition \\
ICE & Internal Combustion Engine \\
IFS & Internal Feedback System \\
ILC & Iterative Learning Control \\
IVC & Intake Valve Closing \\
IVO & Intake Valve Opening \\
LIVC & Late Intake Valve Closing \\
\hline \hline
\end{tabular}


Table A.1 - continued from previous page

\begin{tabular}{|l|l|}
\hline Acronym & Meaning \\
\hline \hline mph & Miles Per Hour \\
NTELC & Non-throttled Engine Load Control \\
RPM & Revolutions Per Minute \\
SI & Spark-Ignition \\
TDC & Top Dead Center \\
\hline \hline
\end{tabular}

